\title{
Near-IR Absorption and Photocurrent Generation Using a First-of- Its-Kind Boron Difluoride Formazanate Non-Fullerene Acceptor
}

\author{
Josh D. B. Koenig ${ }^{\mathrm{a}}$, Mahmoud E. Farahat ${ }^{\mathrm{a}}$, Jasveer S. Dhindsa ${ }^{\mathrm{b}}$, Joe B. Gilroy*b, \\ and Gregory C. Welch*a \\ a Department of Chemistry, University of Calgary, Calgary, Alberta, Canada T2N 1N4. \\ ${ }^{\mathrm{b}}$ Department of Chemistry and the Centre for Advanced Materials and Biomaterials Research \\ (CAMBR), The University of Western Ontario, London, ON, Canada N6A 5B7. \\ * Corresponding Authors: \\ Email: joe.gilroy@uwo.ca; \\ Phone Number: 1-519-661-2111 (ext. 81561) \\ Email: gregory.welch@ucalgary.ca; \\ Phone number: 1-403-210-7603
}

\section{- Abstract}

Herein, we report the synthesis and characterization of the first non-fullerene acceptor (NFA) containing a boron difluoride formazanate $\left(\mathbf{B F}_{2} \mathbf{f z}\right)$ core end-capped with $\mathrm{N}$-annulated perylene diimides (PDIs). Electronic coupling between the BF $\mathbf{2} \mathbf{f z}$ core and the PDI endcaps enabled tuning of the lowest unoccupied molecular orbital, leading to near-panchromatic optical absorption. Postdeposition solvent vapor annealing of the new NFA resulted in a significant red-shift in the optical spectra, which stretched into the near-IR. Proof-of-concept organic photovoltaic (OPV) devices were constructed to demonstrate the potential of this new material as an NFA. SVA treatment of the active layer resulted in a 2 -fold increase in power conversion efficiency (PCE), due mainly to increases in the $\mathbf{B F}_{2} \mathbf{P D I} 2$ generated photocurrent that extended into the near-IR. 


\section{- Introduction}

For applications in organic photovoltaics (OPVs), $\pi$-conjugated materials are perfectly suited for use as non-fullerene acceptors (NFAs) because both physical and optoelectronic properties may be optimized to match the electron-donor material with which they are paired in the active layer. 1,2 One class of non-fullerene acceptors (NFAs) recognized for high redox and thermal stability, as well as high molar absorptivity, are perylene diimides (PDIs). ${ }^{3,4}$ Despite such favorable qualities, the efficiency of charge-extraction for PDI-based NFA materials is often hindered by the formation of large $\pi-\pi$ stacking domains throughout the BHJ. ${ }^{1}$ To promote more favorable phase separation in the BHJ, PDI self-assembly may be disrupted through either direct dimerization of PDIs $^{5-7}$ or insertion of a core between the PDI-moieties. ${ }^{8-19}$
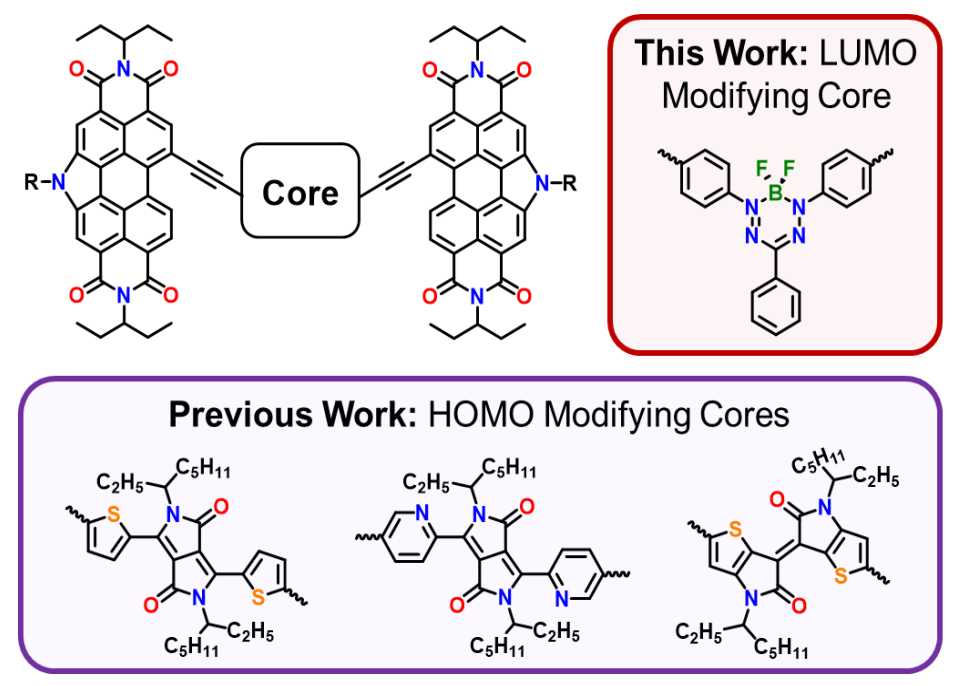

Fig. 1 Depicting previously investigated HOMO-modifying and newly synthesized LUMOmodifying $\mathrm{N}$-annulated PDI-core-PDI materials.

Our research group has previously explored the optoelectronic influence of thienoisoindigo, thienyl- and pyridyl- diketopyrrolopyrrole cores that were acetylene-linked to N-annulated PDI (Fig. 1). ${ }^{20}$ Strong electronic communication between the cores and PDI endcaps adjusted the highest occupied molecular orbital (HOMO) energy level of these molecules, affording nearpanchromatic absorptions ideally suited for OPV. In search of a core that could achieve similar absorptivity, while instead influencing the lowest unoccupied molecular (LUMO) energy level, we targeted an acetylene-terminated boron difluoride formazanate ( $\left.\mathbf{B F}_{2} \mathbf{f} \mathbf{z}\right){ }^{21-23}$ The properties of $\mathbf{B F}_{2} \mathbf{f z}$ materials are highly sensitive to structural variation at the $\mathrm{N}$-aryl substituents, ${ }^{24-26}$ meaning the optoelectronic properties can be tuned by the choice of endcap material. In this contribution, we report the synthesis, characterization, and NFA capability of a new $\pi$-conjugated material comprised of a BF2fz core acetylene-linked to N-annulated PDI endcaps (BF2PDI2). 


\section{- Characterization}

The $\mathbf{B F}_{2} \mathbf{f} \mathbf{z}$ core and $\mathrm{N}$-annulated PDI end caps were connected via a Sonogashira cross-coupling reaction to generate $\mathbf{B F}_{2} \mathbf{P D I}_{2}$ (see Supporting Information for full experimental details). The identity of $\mathbf{B F}_{2} \mathbf{P D I}_{2}$ was confirmed by ${ }^{1} \mathrm{H},{ }^{11} \mathrm{~B},{ }^{13} \mathrm{C}$, and ${ }^{19} \mathrm{~F}$ NMR spectroscopy, as well as MALDI TOF mass spectrometry and CHN elemental analysis (Figs. S1-7). The ${ }^{11} \mathrm{~B}$ and ${ }^{19} \mathrm{~F}$ NMR spectra exhibited diagnostic 1:2:1 triplet and 1:1:1:1 quartet coupling patterns, respectively. ${ }^{24}$ Moreover, the ${ }^{1} \mathrm{H}$ NMR spectrum showed no evidence of a formazan related N-H peak (at $\left.\sim 15 \mathrm{ppm}\right),{ }^{21}$ strongly suggesting the $\mathbf{B F} \mathbf{2} \mathbf{f z}$ core remained intact throughout synthesis and purification.

The thermal properties of $\mathbf{B F}_{2} \mathbf{P D I}_{2}$ were measured using a combination of differential scanning calorimetry and thermal gravimetric analysis (Figs. S8-9). No obvious glass transitions or melting points were observed between $100-300{ }^{\circ} \mathrm{C}$, while the onset of molecular decomposition was not observed until $>300{ }^{\circ} \mathrm{C}$. The high thermal stability observed in $\mathbf{B F}_{2} \mathbf{P D I}_{2}$ may be attributed to significant $\pi$-conjugation between the $\mathbf{B F}_{2} \mathbf{f z}$ core and the $\mathrm{N}$-annulated PDI endcaps. This notion was supported by the density functional theory (DFT) optimized structure of $\mathbf{B F}_{\mathbf{2}} \mathbf{P D I}_{2}$ at the B3LYP-6-31G(d,p) level of theory (Fig. S13). The PDI units were nearly co-planar with each other, with only a small degree of bending caused by the $\mathbf{B F} \mathbf{2} \mathbf{z}$ core. This DFT optimized 'dragonfly' structure corresponded well with previously determined X-ray crystallography structures for compounds using the same $\mathbf{B F} 2 \mathbf{f z}$ core. ${ }^{22,23}$

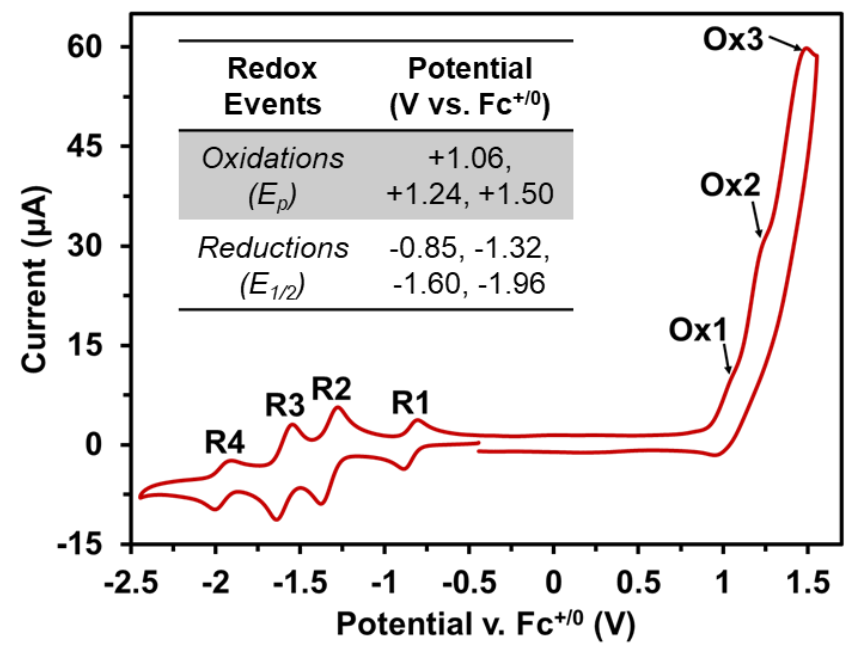

Fig. 2 Cyclic voltammogram of $\mathrm{BF}_{2} \mathrm{PDI}_{2}$, measured at $100 \mathrm{mV} / \mathrm{s}$ in $\mathrm{CH}_{2} \mathrm{Cl}_{2}$ under argon with 0.1 $\mathrm{M} \mathrm{TBAPF}_{6}$ supporting electrolyte $(\mathrm{WE}=$ glassy carbon, $\mathrm{CE}=\mathrm{Pt}$-wire, pseudo- $\mathrm{RE}=\mathrm{Ag} / \mathrm{AgCl}$ ). Inset are all measured oxidation $(\mathrm{Ox})$ and reduction $(\mathrm{R})$ events, referenced to $\mathrm{Fc}^{+/ 0}$.

Next, the electronic properties of $\mathbf{B F}_{2} \mathbf{P D I}_{2}$ were probed using cyclic voltammetry (CV), with additional information provided by DFT calculations. The CV of $\mathbf{B F}_{2} \mathbf{P D I}_{2}$ was comprised of three irreversible oxidation events, as well as four fully reversible reduction events (Fig. 2). While the number oxidation events could be determined by differential pulse voltammetry (Fig. S12), the precise electrochemical origin may not be readily assigned. On the other hand, the first and fourth 
reductions $\left(\mathrm{E}_{1 / 2}=-0.85\right.$ and $-1.96 \mathrm{~V}$ vs. $\left.\mathrm{Fc}^{+/ 0}\right)$ may be attributed to $\mathbf{B F}_{2} \mathbf{f} \mathbf{z}$ core, while the second and third reduction events $\left(\mathrm{E}_{1 / 2}=-1.32\right.$ and $-1.60 \mathrm{~V}$ vs. $\left.\mathrm{Fc}^{+/ 0}\right)$ may be attributed to $\mathrm{N}$-annulated PDI as the current passed during these redox processes was $2 x$ larger. By DFT calculations, the first oxidation event appeared to be delocalized across the entire molecule, while the first reduction event was largely centered on the $\mathbf{B F}_{2} \mathbf{f} \mathbf{z}$ core (Fig. S14). These predicted HOMO-LUMO energy levels correlate well with the observed CV data. Together, these data strongly suggest that the $\mathbf{B F}_{2} \mathbf{f z}$ core has a higher electron affinity than the $\mathrm{N}$-annulated PDI endcaps, which served to lower the LUMO energy level of $\mathbf{B F}_{2} \mathbf{P D I}$, when compared to related compounds with different cores. ${ }^{20}$

The optical properties of $\mathbf{B F}_{2} \mathbf{P D I}_{2}$ were measured by UV-visible-nearIR absorption spectroscopy (UV-vis-nIR). The UV-vis-nIR profile of $\mathbf{B F}_{2} \mathbf{P D I}_{2}$ in solution possessed a broad absorbance between $450-750 \mathrm{~nm}$, with an absorption maximum $\left(\lambda_{\max }\right)$ at $543 \mathrm{~nm}$ attributable to the PDI endcaps (Fig. 3). When spin-cast into a thin-film, the optical profile of $\mathbf{B F}_{2} \mathbf{P D I} \mathbf{I}_{2}$ underwent several notable changes. Beyond the slightly red-shifted onset of absorption $\left(\lambda_{\text {onset }}\right)$, the broadening of $\lambda_{\max }$ was also accompanied by an appreciable increase in the intensity of the low-energy intramolecular charge transfer (ICT) band. ${ }^{20}$

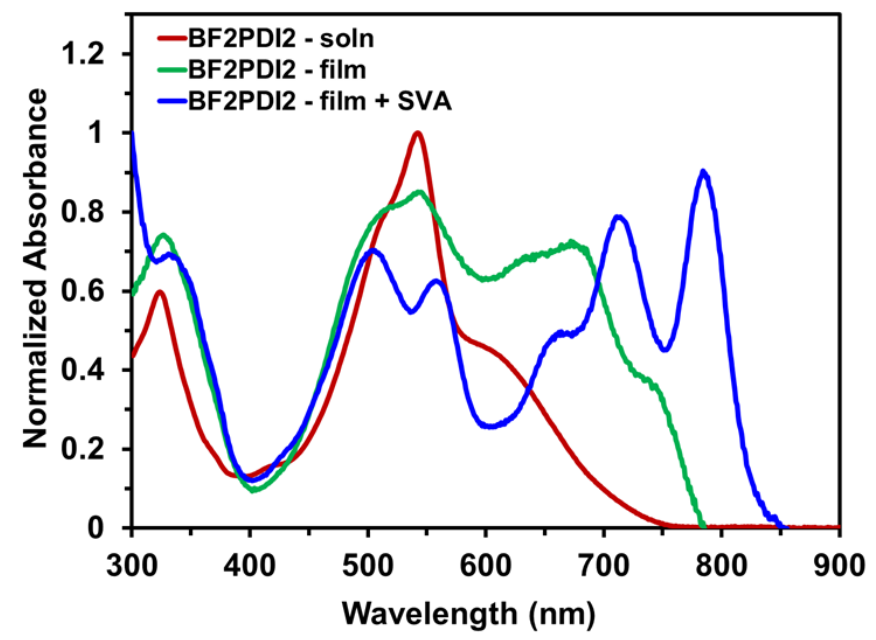

Fig. $3 \mathrm{UV}$-vis absorption profile of $\mathrm{BF}_{2} \mathrm{PDI}_{2}$ in $\mathrm{CHCl}_{3}$ solution (red), thin-film spin-cast from $o$ dichlorobenzene (green), and the same thin-film solvent vapor annealed from $\mathrm{CHCl}_{3}$ (blue).

In the past, we have shown that post-deposition solvent vapor annealing (SVA) can induce structural order within the solid-state morphology of similar PDI-core-PDI materials. ${ }^{10,27-30}$ Exposure of this thin-film to $\mathrm{CHCl}_{3}$ solvent vapors caused the once broad solid-state optical profile to resolve into two distinct absorption regions. The PDI-based $\lambda_{\max }$ region was split into two peaks $(\lambda=508$ and $560 \mathrm{~nm})$, while the low-energy ICT shoulder developed fine structure $\left(\lambda_{\max }=790\right.$ $\mathrm{nm})$ that extended well into the near-IR $\left(\lambda_{\text {onset }}=850 \mathrm{~nm}\right)$. This behaviour is strongly indicative of reorganization and/or aggregation of $\mathbf{B F}_{2} \mathbf{P D I}_{2}$ into more ordered domains in the solid-state. ${ }^{31-33}$ 


\section{- OPV Devices}

The NFA capabilities of $\mathbf{B F}_{2} \mathbf{P D I}_{2}$ were assessed by constructing some proof-of-concept OPV devices with the following inverted architecture: ITO/ZnO/Ternary Active Layer/MoOx/Ag (full experimental details in SI). A ternary active layer comprised of electron-donor polymer PPDT2FBT (FBT), PC ${ }_{61} \mathrm{BM}_{\text {, and }} \mathbf{B F}_{2} \mathbf{P D I}_{2}$ was employed for OPV devices. FBT was selected because of its complementary absorption with the solvent vapor annealed $\mathbf{B F}_{2} \mathbf{P D I}_{2}$ (Fig. S15). $\mathrm{PC}_{61} \mathrm{BM}$ was added to this ternary blend to assist with charge mobility. ${ }^{34}$ Using an initial

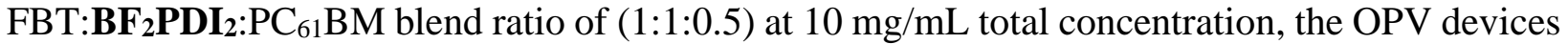
achieved a open circuit voltage $\left(\mathrm{V}_{\mathrm{oc}}\right)$ of $0.69 \mathrm{~V}$, a short circuit current $\left(\mathrm{J}_{\mathrm{sc}}\right)$ of $1.1 \mathrm{~mA} / \mathrm{cm}^{2}$, and a fill factor (FF) of $41 \%$, leading to a power conversion efficiency (PCE) of $0.3 \%$.

Post-deposition treatment of these films with $\mathrm{CHCl}_{3} \mathrm{SVA}$ resulted in the desired optical profile shift of $\mathbf{B F}_{2} \mathbf{P D I}$, giving the OPV devices a near-panchromatic absorbance (Fig. 4A). Device performance was maximized after 5 mins of $\mathrm{CHCl}_{3} \mathrm{SVA}$, where both the $\mathrm{J}_{\mathrm{sc}}$ and $\mathrm{FF}$ increased to $1.9 \mathrm{~mA} / \mathrm{cm}^{2}$ and $49 \%$, respectively, leading to a 2-fold increase in PCE to $0.6 \%$ (Fig. 4B). Longer SVA treatments led to OPV performances similar to as-cast devices (Fig. S16 and Table S2). This phenomena has previously been observed with our N-annulated PDI-core-PDI materials and was attributed to over-annealing of the active layer. ${ }^{10,27}$ Further attempts to optimize the ternary blend by altering the $\mathrm{FBT}: \mathbf{B F}_{2} \mathbf{P D I} 2: \mathrm{PC}_{61} \mathrm{BM}$ ratio and/or increasing total concentration were found to improve as-cast devices (Fig. S17 and Table S3). However, following SVA treatment of these devices, overall OPV performance was negatively impacted.
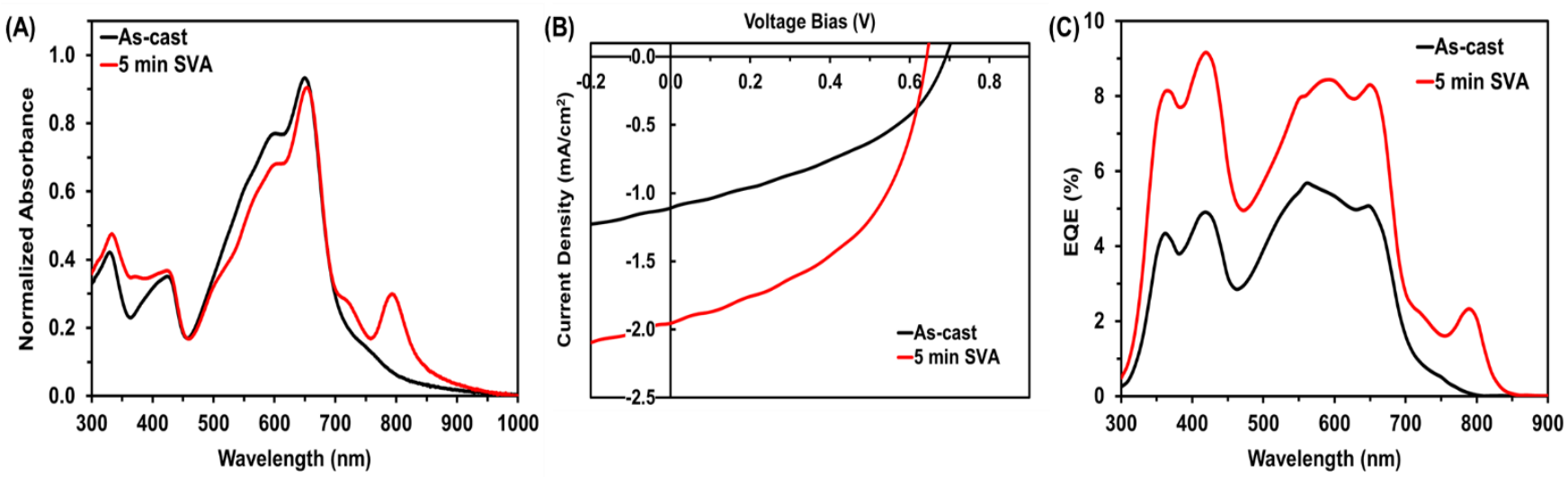

Fig. 4 Optical absorption profile (A), J-V curves (B), an external quantum efficiency plots (C) comparing the effects of solvent vapor annealing on ternary blend OPV devices with a FBT:BF $\mathrm{PDI}_{2}: \mathrm{PC}_{61} \mathrm{BM}(1: 1: 0.5)$ active layer at $10 \mathrm{mg} / \mathrm{mL}$ total concentration.

To better understand the observed enhancement in OPV performance for $F B T: \mathbf{B F}_{2} \mathbf{P D I}_{2}: \mathrm{PC}_{61} \mathrm{BM}$ (1:1:0.5) ternary blends that were solvent vapor annealed from $\mathrm{CHCl}_{3}$ for 5 min, photoluminescence (PL) and external quantum efficiency (EQE) experiments were performed. PL measurements of the ternary blend showed efficient quenching of the FBT polymer before and 
after SVA treatment (Fig. S18). Analysis of the EQE spectra, the measured photocurrent clearly displays contributions from all components of the ternary blend (Fig. 4C). Following SVA treatment, photocurrent generation was extended well into the near-IR $\left(\lambda_{\max }=790 \mathrm{~nm}\right)$, clearly emphasizing the increased contribution from the new NFA material, $\mathbf{B F}_{2} \mathbf{P D I}_{2}$.

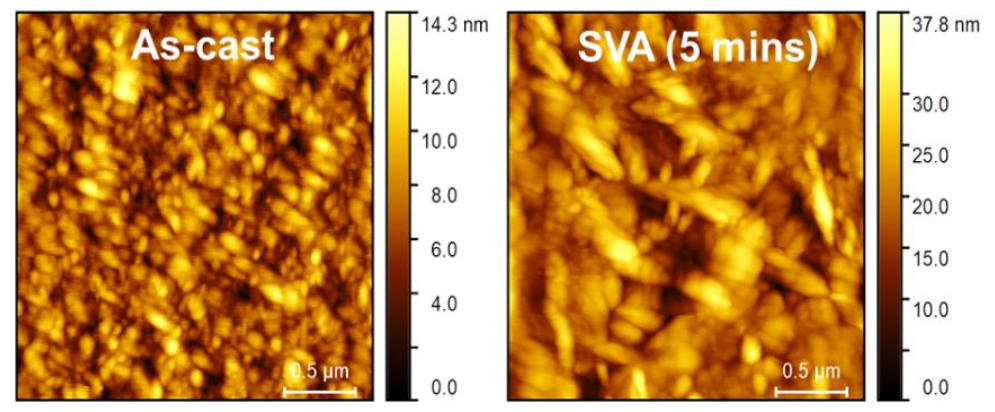

Fig. 5 Atomic force microscopy height images of ternary blend OPV devices with an FBT: $\mathrm{BF}_{2} \mathrm{PDI}_{2}: \mathrm{PC}_{61} \mathrm{BM}(1: 1: 0.5)$ active layer at $10 \mathrm{mg} / \mathrm{mL}$ total concentration.

Surface morphology differences between the as-cast and SVA treated devices were also monitored by atomic force microscopy (AFM). AFM height images showed significant differences between the as-cast and SVA treated devices (Fig. 5), as the root-mean square surface roughness of the films increased from $1.9 \mathrm{~nm}$ to $4.8 \mathrm{~nm}$. X-ray diffraction (XRD) measurements of ternary blend films before and after $\mathrm{CHCl}_{3}$ SVA failed to show any distinguishing features that could be attributed to $\mathbf{B F}_{2} \mathbf{P D I}_{2}$ (Fig. S19). ${ }^{35}$ Together, these data strongly suggest that SVA enhanced OPV performance by inducing favorable $\mathbf{B F}_{2} \mathbf{P D I}_{2}$ aggregation, rather than self-assembly into crystalline domains. ${ }^{27,31-33}$

\section{- Conclusions}

In conclusion, we have synthesized and fully characterized a first-of-its-kind NFA containing a $\mathbf{B F}_{2} \mathbf{f z}$ core. The use of acetylene-linkers enabled through-conjugation between the $\mathbf{B F}_{2} \mathbf{f z}$ core and the PDI endcaps, leading to an altered LUMO energy level that resulted in near-panchromatic absorption for $\mathbf{B F}_{2} \mathbf{P D I}_{2}$. Treatment of solid-state $\mathbf{B F}_{2} \mathbf{P D I}_{2}$ with $\mathrm{CHCl}_{3}$ SVA resulted in a significant bathochromic shift of the optical spectra, leading to near-IR absorption. The overall performance in a series of proof-of-concept OPV devices, where $\mathrm{BF}_{2} \mathrm{PDI}_{2}$ was used as an NFA in the ternary blend, was improved 2-fold by SVA treatment of the active layer. The increase in PCE could be mainly attributed to favorable aggregation of $\mathbf{B F}_{2} \mathbf{P D I}_{2}$ in the active layer which increased the generated photocurrent. This notion was supported by EQE and AFM measurements. This work demonstrates the utility of the $\mathbf{B F}_{2} \mathbf{f} \mathbf{z}$ organic dye to construct narrow bandgap $\pi$-conjugated materials for use in organic electronics and provides the groundwork for further development. 


\section{- Acknowledgements}

GCW acknowledges the Canada Research Chairs Program, CFI JELF (34102), NSERC DG (201904392), and the University of Calgary. JBG acknowledges CFI JELF (33977), NSERC DG (201804240), and the University of Western Ontario. JSD acknowledges NSERC CGS-D Scholarship. JK acknowledges Alberta Graduate Excellence Scholarship (AGES) program. This research was undertaken thanks in part to funding from the Canada First Research Excellence Fund (CFREF).

\section{- References}

1 S. Rajaram, R. Shivanna, S. K. Kandappa and K. S. Narayan, J. Phys. Chem. Lett., 2012, 3, 2405-2408.

2 C. B. Nielsen, S. Holliday, H.-Y. Chen, S. J. Cryer and I. McCulloch, Acc. Chem. Res., 2015, 48, 2803-2812.

3 Z. Liu, Y. Wu, Q. Zhang and X. Gao, J. Mater. Chem. A, 2016, 4, 17604-17622.

4 W. Chen and Q. Zhang, J. Mater. Chem. C, 2017, 5, 1275-1302.

5 D. Sun, D. Meng, Y. Cai, B. Fan, Y. Li, W. Jiang, L. Huo, Y. Sun and Z. Wang, J. Am. Chem. Soc., 2015, 137, 11156-11162.

6 D. Meng, D. Sun, C. Zhong, T. Liu, B. Fan, L. Huo, Y. Li, W. Jiang, H. Choi, T. Kim, J. Y. Kim, Y. Sun, Z. Wang and A. J. Heeger, J. Am. Chem. Soc., 2016, 138, 375-380.

7 A. D. Hendsbee, J.-P. Sun, W. K. Law, H. Yan, I. G. Hill, D. M. Spasyuk and G. C. Welch, Chem. Mater., 2016, 28, 7098-7109.

8 Y. Lin, Y. Wang, J. Wang, J. Hou, Y. Li, D. Zhu and X. Zhan, Adv. Mater., 2014, 26, 51375142.

9 Y. Duan, X. Xu, H. Yan, W. Wu, Z. Li and Q. Peng, Adv. Mater., 2017, 29, 1605115.

10 S. M. McAfee, S. V. Dayneko, P. Josse, P. Blanchard, C. Cabanetos and G. C. Welch, Chem. Mater., 2017, 29, 1309-1314.

11 J. Liu, S. Xie, S. Feng, M. Li, L. Wu, X. Xu, X. Chen, C. Li and Z. Bo, J. Mater. Chem. C, 2018, 6, 9336-9340.

12 H. Lin, S. Chen, H. Hu, L. Zhang, T. Ma, J. Y. L. Lai, Z. Li, A. Qin, X. Huang, B. Tang and H. Yan, Adv. Mater., 2016, 28, 8546-8551.

13 Q. Wu, D. Zhao, A. M. Schneider, W. Chen and L. Yu, J. Am. Chem. Soc., 2016, 138, 72487251 .

14 J. Zhang, Y. Li, J. Huang, H. Hu, G. Zhang, T. Ma, P. C. Y. Chow, H. Ade, D. Pan and H. Yan, J. Am. Chem. Soc., 2017, 139, 16092-16095.

15 Q. Zhang, X. Xut, S. Chenћ, G. B. Bodedla, M. Sun, Q. Hu, Q. Peng, B. Huang, H. Ke, F. Liu, T. P. Russell and X. Zhu, Sustain. Energy Fuels, 2018, 2, 2616-2624.

16 T. A. Welsh, A. Laventure, T. Baumgartner and G. C. Welch, J. Mater. Chem. C, 2018, 6, 2148-2154.

17 T. A. Welsh, A. Laventure, A. F. Alahmadi, G. Zhang, T. Baumgartner, Y. Zou, F. Jäkle and G. C. Welch, ACS Appl. Energy Mater., 2019, 2, 1229-1240.

18 Z. Luo, T. Liu, Z. Chen, Y. Xiao, G. Zhang, L. Huo, C. Zhong, X. Lu, H. Yan, Y. Sun and C. Yang, Adv. Sci., 2019, 6, 1802065. 
19 J. D. B. Koenig, A. Laventure and G. C. Welch, ACS Appl. Energy Mater., 2019, 2, 89398945.

20 J. R. Cann, C. Cabanetos and G. C. Welch, ChemPlusChem, 2017, 82, 1359-1364.

21 S. M. Barbon and J. B. Gilroy, Polym. Chem., 2016, 7, 3589-3598.

22 J. S. Dhindsa, R. R. Maar, S. M. Barbon, M. O. Avilés, Z. K. Powell, F. Lagugné-Labarthet and J. B. Gilroy, Chem. Commun., 2018, 54, 6899-6902.

23 J. S. Dhindsa, A. Melenbacher, S. M. Barbon, M. J. Stillman and J. B. Gilroy, Dalton Trans., , DOI:10.1039/C9DT03417J.

24 R. R. Maar, S. M. Barbon, N. Sharma, H. Groom, L. G. Luyt and J. B. Gilroy, Chem. - Eur. J., 2015, 21, 15589-15599.

25 R. R. Maar, R. Zhang, D. G. Stephens, Z. Ding and J. B. Gilroy, Angew. Chem. Int. Ed., 2019, 58, 1052-1056.

26 J. B. Gilroy and E. Otten, Chem. Soc. Rev., 2020, 49, 85-113.

27 S. M. McAfee, A.-J. Payne, S. V. Dayneko, G. P. Kini, C. E. Song, J.-C. Lee and G. C. Welch, J. Mater. Chem. A, 2017, 5, 16907-16913.

28 S. M. McAfee, A.-J. Payne, A. D. Hendsbee, S. Xu, Y. Zou and G. C. Welch, Sol. RRL, 2018, 2, 1800143.

29 D. Zomerman, J. Kong, S. M. McAfee, G. C. Welch and T. L. Kelly, ACS Appl. Energy Mater., 2018, 1, 5663-5674.

30 A.-J. Payne, N. A. Rice, S. M. McAfee, S. Li, P. Josse, C. Cabanetos, C. Risko, B. H. Lessard and G. C. Welch, ACS Appl. Energy Mater., 2018, 1, 4906-4916.

31 A.-J. Payne, S. Li, S. V. Dayneko, C. Risko and G. C. Welch, Chem. Commun., 2017, 53, 10168-10171.

32 M. E. Farahat, C.-S. Tsao, Y.-C. Huang, S. Hsiung Chang, W. Budiawan, C.-G. Wu and C.W. Chu, J. Mater. Chem. A, 2016, 4, 7341-7351.

33 T. H. Lee, S. Y. Park, B. Walker, S.-J. Ko, J. Heo, H. Y. Woo, H. Choi and J. Y. Kim, RSC Adv., 2017, 7, 7476-7482.

34 S. B. Srivastava, S. K. Srivastava and S. P. Singh, J. Phys. Chem. C, 2017, 121, 1710417111.

35 F. Tintori, A. Laventure and G. C. Welch, Soft Matter, 2019, 15, 5138-5146. 


\section{Near-IR Absorption and Photocurrent Generation Using a First-of- Its-Kind Boron Difluoride Formazanate Non-Fullerene Acceptor}

\section{(Supporting Information)}

Josh D. B. Koenig ${ }^{\mathrm{a}}$, Mahmoud E. Farahat ${ }^{\mathrm{a}}$, Jasveer S. Dhindsa ${ }^{\mathrm{b}}$, Joe B. Gilroy*b and Gregory C. Welch*a

${ }^{\text {a }}$ Department of Chemistry, University of Calgary, Calgary, Alberta, Canada T2N 1N4.

${ }^{\mathrm{b}}$ Department of Chemistry and the Centre for Advanced Materials and Biomaterials Research (CAMBR), The University of Western Ontario, London, ON, Canada N6A 5B7.

* Corresponding Authors:

Email: joe.gilroy@uwo.ca;

Phone Number: 1-519-661-2111 (ext. 81561)

Email: gregory.welch@ucalgary.ca;

Phone number: 1-403-210-7603

Keywords: $\mathrm{BF}_{2}$ formazanate; non-fullerene acceptor; perylene diimide; PDI; Near-IR; OPV

\section{TABLE OF CONTENTS}

1. Methods and Materials $\quad$ S2-S3

2. Synthetic/Experimental Procedures $\quad$ S4

$\begin{array}{ll}\text { 3. NMR Spectroscopy } & \text { S5-S7 }\end{array}$

4. MS, CHN EA, \& Thermal Properties S8-S9

5. UV-Visible Spectroscopy $\quad$ S10

6. Electrochemistry $\quad$ S11

$\begin{array}{ll}\text { 7. Density Functional Theory } & \mathbf{S 1 2}\end{array}$

8. OPV Device Data $\quad$ S13-S16

$\begin{array}{ll}\text { 9. References } & \text { S17 }\end{array}$ 


\section{Methods and Materials}

Materials: FBT polymer donor: poly[(2,5-bis(2-hexyldecyloxy) phenylene)-alt-(5,6-difluoro-4,7di(thiophen-2-yl)benzo[c][1,2,5]thiadiazole)] (PPDT2FBT) was purchased from Brilliant Matters. Fullerene acceptor [6,6]-phenyl- $\mathrm{C}_{61}$-butyric acid methyl ester $\left(\mathrm{PC}_{61} \mathrm{BM}\right)$ was purchased from Ossila. All other reactants, reagents, and catalysts were purchased from Sigma-Aldrich or VWR and used without further purification.

CHN Elemental Analysis: Elemental analyses were performed by Jian Jun (Johnson) Li in the Chemical Instrumentation Facility at the University of Calgary. A Perkin Elmer 2400 Series II CHN Elemental Analyzer was used to obtain $\mathrm{CHN}$ data, using $~ 1.5 \mathrm{mg}$ of sample (with particle sizes ranging between 0.2 and $0.5 \mathrm{~mm}$ in diameter).

Nuclear Magnetic Resonance (NMR): All NMR spectroscopy experiments were recorded using a Bruker Avance III $500 \mathrm{MHz}$ spectrometer. All experiments were performed in tetrachloroethane$\mathrm{d}_{2}$. Chemical shifts (referenced to residual solvent) were reported in parts per million (ppm). Multiplicities were reported as follows: singlet (s), doublets (d), triplets (t), quartet (q), pentet (p), doublet of doublets $(\mathrm{dd})$, doublet of triplets $(\mathrm{dt})$, doublet of quartets $(\mathrm{dq})$, triplet of doublets $(\mathrm{td})$, triplet of triplets $(\mathrm{tt})$, and multiplets $(\mathrm{m})$.

High-resolution MALDI-TOF (HR MALDI-TOF): High-resolution MALDI-TOF mass spectrometry measurements were performed by Johnson $\mathrm{Li}$ in the Chemical Instrumentation Facility at the University of Calgary. The sample solution $(\sim 1 \mu \mathrm{g} / \mathrm{mL}$ in dichloromethane $)$ was mixed with matrix trans2-[3-(4-tert-Butylphenyl)-2-methyl-2-propenylidene]malononitrile (DCTB) solution $(\sim 5 \mathrm{mg} / \mathrm{mL}$ in methanol). All spectra were acquired using a Bruker Autoflex III Smartbeam MALDI-TOF, set to the positive reflective mode (Na:YAG $355 \mathrm{~nm}$ laser settings: laser offset $=62-69$; laser frequency $=200 \mathrm{~Hz}$; and number of shots $=300)$. The target used was Bruker MTP 384 ground steel plate target.

UV-Visible Spectroscopy (UV-Vis): All absorption measurements were recorded using Agilent Technologies Cary $60 \mathrm{UV}-\mathrm{V}$ is spectrometer at room temperature. All solution UV-Vis spectra were measured with $2 \mathrm{~mm}$ quartz cuvettes, using $\mathrm{CHCl}_{3}$ as solvent. Stock solutions $(\sim 1.0 \mathrm{mg} / \mathrm{mL})$ of each compound were prepared, serially diluted to concentrations between $10^{-5}-10^{-6} \mathrm{M}$, and then used to construct calibration curves for determining molar absorptivity. Neat films were prepared by spin-coating from a $1 \% \mathrm{wt} / \mathrm{v}$ solution onto clean Corning glass slides. Prior to use, glass slides were cleaned with soap and water, acetone and isopropanol, and followed by UV/ozone treatment using a Novascan UV/ozone cleaning system.

Photoluminescence (PL): All emission measurements were recorded using an Agilent Technologies Cary Eclipse fluorescence spectrophotometer at room temperature.

Atomic Force Microscopy (AFM): AFM measurements were performed by using a TT2-AFM (AFM Workshop) in tapping mode and WSxM software with an 0.01-0.025 Ohm/cm Sb (n) doped $\mathrm{Si}$ probe with a reflective back side aluminum coating. Samples for AFM measurement were the same ones that were used to collect the respective the device parameters. 
X-Ray Diffraction (XRD): All X-ray diffraction experiments were performed with a PROTO AXRD Benchtop Powder Diffractometer using $\theta-2 \theta$ scans and $\mathrm{Cu} K-\alpha$ radiation

Cyclic Voltammetry (CV): Electrochemical measurements were performed using a $\mathrm{CH}$ Instruments Inc. Model 1200B Series Handheld Potentiostat. A standard 3-electrode setup was utilized, consisting of a freshly polished glassy carbon disk working electrode (WE), Pt-wire counter electrode (CE), and Ag-wire pseudo-reference electrode (RE). All measurements were referenced to ferrocene $\left(\mathrm{Fc}^{+/ 0}\right)$ as internal standard. All cyclic voltammetry experiments were performed at a scan rate of $100 \mathrm{mV} / \mathrm{s}$. Sample solutions, with $1 \mathrm{mM}$ compound and $0.1 \mathrm{M}$ tetrabutylammonium hexafluorophosphate $\left(\mathrm{TBAPF}_{6}\right)$ supporting electrolyte, were prepared in anhydrous $\mathrm{CH}_{2} \mathrm{Cl}_{2}$. All electrochemical solutions were sparged with dry gas (either $\mathrm{N}_{2}$ or argon) for 5 minutes to deoxygenate the system prior to measurements. The ionization potentials (IP) and electron affinities (EA) were estimated by correlating the $1^{\text {st }}$ oxidation and $1^{\text {st }}$ reduction potentials $\left(\mathrm{E}_{\mathrm{p}}\right.$ ox $\mathrm{Fc}^{0 /+}, \mathrm{E}_{1 / 2} \mathrm{red} \mathrm{Fc}^{0 /+}$ ) to the normal hydrogen electrode (NHE), assuming the IP of $\mathrm{Fc}^{0 /+}$ to be $4.80 \mathrm{eV}$, respectively. ${ }^{1}$

Power Conversion Efficiency (PCE) and External Quantum Efficiency (EQE): The current density-voltage $(\mathrm{J}-\mathrm{V})$ curves were measured by a Keithley 2420 source measure unit. The photocurrent was measured under AM 1.5 illumination at $100 \mathrm{~mW} / \mathrm{cm}^{2}$ under a Solar Simulator (Newport 92251A-1000). The standard silicon solar cell (Newport 91150V) was used to calibrate light intensity. EQE was measured in a QEX7 Solar Cell Spectral Response/QE/IPCE Measurement System (PV Measurement, Model QEX7, USA) with an optical lens to focus the light into an area about $0.04 \mathrm{~cm}^{2}$, smaller than the dot cell. The silicon photodiode was used to calibrate the EQE measurement system in the wavelength range from 300 to $1100 \mathrm{~nm}$.

Organic Photovoltaic (OPV) Devices: Inverted device architecture (ITO/ZnO/Ternary Active Layer/MoOx/Ag) was used in OPVs device fabrication. Devices were fabricated using ITO-coated glass substrates cleaned by sequentially ultra-sonicating with detergent and de-ionized water, acetone, and isopropanol followed by exposure to UV/ozone for $30 \mathrm{~min}$. $\mathrm{ZnO}$ was subsequently deposited as a sol-gel precursor solution in a $\mathrm{N}_{2}$ purge box following the method of Sun et al. ${ }^{2}$ The ternary blend FBT: $\mathrm{BF}_{2} \mathrm{PDI}_{2}$ : $\mathrm{PC}_{61} \mathrm{BM}$ was dissolved in dichlorobenzene at 1:1:0.5 weight ratio (total concentration of $10 \mathrm{mg} / \mathrm{mL}$ ) and processed in air at room temperatures. The substrates with the cast active layers were kept in an $\mathrm{N}_{2}$ atmosphere glovebox overnight before evaporating $\mathrm{MoO}_{3}$ and $\mathrm{Ag}$. The $10 \mathrm{~nm}$ of $\mathrm{MoO}_{3}$ followed by $100 \mathrm{~nm}$ of $\mathrm{Ag}$ were thermally deposited under vacuum $\left(10^{-5}\right.$ Torr $)$. Active areas of the devices were $0.14 \mathrm{~cm}^{2}$.

Computational Details: Gas-phase B3LYP/6-31G(d,p) ground-state equilibrium geometry optimizations were considered within Gaussian $09 .{ }^{3}$ To reduce the computational cost, all alkylsubstituents were truncated to methyl groups. Molecular dihedral angles were systematically altered to ensure that the optimized geometric lower energy minimum was not missed structure possessed no imaginary frequencies. The resulting structure was characterized through frequency calculations (at the same level of theory). TD-SCF calculations were also performed from this optimized geometry. Single point calculations were performed on this structure to generate molecular orbitals and electrostatic potential maps. 


\section{Synthetic/Experimental Procedures}

\section{Boron Difluoride Formazanate (EthylHexyl-N-annulated Perylene Diimide)2 $\left(\mathrm{BF}_{2} \mathrm{PDI}_{2}\right)$}

Starting materials 2,6-bis(4-ethynylphenyl)-4-phenyl-1- $\mathrm{BF}_{2}$-formazanate $\left(\mathrm{BF}_{2} \mathrm{Ace}_{2}\right)$ and ethylhexyl$\mathrm{N}$-annulated Perylene Diimide Bromide (EH-NPDI-Br) were prepared following known literature preparations. $^{4,5}$

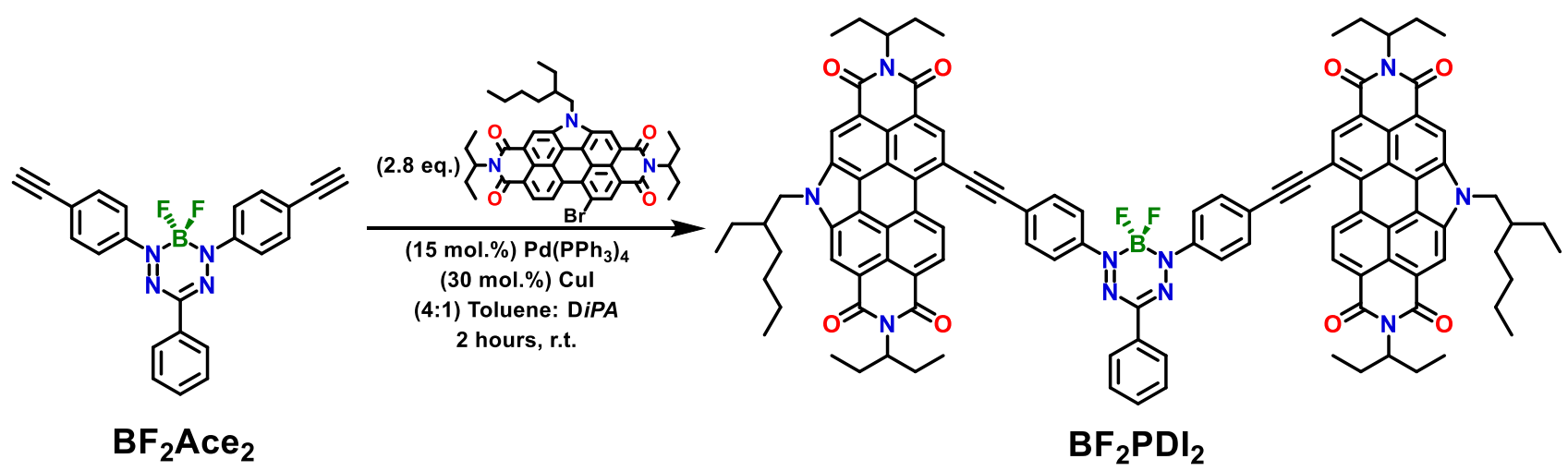

EH-N-PDI-Br (103 mg, 0.14 mmol, 2.8 eq.), $\mathrm{BF}_{2}$ (Ace) $)_{2}$ (19.9 mg, $0.05 \mathrm{mmol}, 1.0$ eq.), and CuI (2.8 $\mathrm{mg}, 0.015 \mathrm{mmol}, 30 \mathrm{~mol} \%$ ) were combined into a $10 \mathrm{~mL} \mu$ wave vial. The vial was brought into the glovebox, $\mathrm{Pd}\left(\mathrm{PPh}_{3}\right)_{4}(8.7 \mathrm{mg}, 0.008 \mathrm{mmol}, 15 \mathrm{~mol} \%)$ was added, and then the vial was sealed. A degassed mixture of toluene:diisopropylamine (4:1) was transferred into the vial using a Cannula line. The reaction mixture was stirred at room temperature for $2 \mathrm{hrs}$ (monitoring reaction progress by TLC) and then subsequently quenched by pouring into $\mathrm{H}_{2} \mathrm{O}(50 \mathrm{~mL})$. The resulting solution was liquid-liquid extracted using $\mathrm{CH}_{2} \mathrm{Cl}_{2}(3 \times 25 \mathrm{~mL})$. The organic extracts were dried over $\mathrm{Na}_{2} \mathrm{SO}_{4}$ and then filtered through a short Celite plug. Organic solvent was removed by rotary evaporation and the resulting crude solid was purified by silica-gel column chromatography (eluting with $\mathrm{CH}_{2} \mathrm{Cl}_{2}$ ). The purified purple solid was precipitated into $\mathrm{MeOH}$ and collected by vacuum filtration (59 $\mathrm{mg}$, $0.035 \mathrm{mmol}, \underline{69 \%})$.

${ }^{1} \mathrm{H}$ NMR $\left(500 \mathrm{MHz}\right.$, Tetrachloroethane-d $\left.\mathrm{d}_{2}\right) \delta 9.67(\mathrm{~d}, J=8.3 \mathrm{~Hz}, 2 \mathrm{H}), 8.46(\mathrm{~s}, 2 \mathrm{H}), 8.41(\mathrm{~s}, 4 \mathrm{H})$, $8.34(\mathrm{~d}, J=8.3 \mathrm{~Hz}, 2 \mathrm{H}), 7.58(\mathrm{dd}, J=19.5,7.6 \mathrm{~Hz}, 5 \mathrm{H}), 7.35(\mathrm{~d}, J=8.4 \mathrm{~Hz}, 4 \mathrm{H}), 6.99-6.88(\mathrm{~m}$, $4 \mathrm{H}), 4.59-4.51(\mathrm{~m}, 4 \mathrm{H}), 4.15(\mathrm{t}, J=8.1 \mathrm{~Hz}, 4 \mathrm{H}), 1.45-1.26(\mathrm{~m}, 8 \mathrm{H}), 0.94-0.55(\mathrm{~m}, 22 \mathrm{H}), 0.39$ $-0.25(\mathrm{~m}, 24 \mathrm{H}), 0.22(\mathrm{t}, J=7.3 \mathrm{~Hz}, 6 \mathrm{H})$.

${ }^{13} \mathrm{C}\left\{{ }^{1} \mathrm{H}\right\}$ NMR $(126 \mathrm{MHz}$, Tetrachloroethane-d 2$) \delta 134.38,132.01,131.59,130.82,127.97,126.06$, $123.35,122.97,122.68,121.37,121.21,119.03,118.38,118.23,116.15,109.40,98.35,78.70$, 78.56, 78.48, 78.25, 73.03, 56.64, 40.27, 29.59, 27.35, 24.12, 23.03, 21.99, 12.99, 10.51, 10.50, 9.56. *quaternary centres were not observed due to limited solubility of $\mathrm{BF}_{2} \mathrm{PDI}_{2}$ *

${ }^{11} \mathrm{~B}$ NMR $\left(161 \mathrm{MHz}\right.$, Tetrachloroethane- $\left.d_{2}\right) \delta-0.47\left(\mathrm{t},{ }^{1} J_{\mathrm{BF}}=28.9 \mathrm{~Hz}, 1 \mathrm{~B}\right)$.

${ }^{19} \mathrm{~F} \mathrm{NMR}\left(471 \mathrm{MHz}\right.$, Tetrachloroethane- $\left.d_{2}\right) \delta-143.24\left(\mathrm{q},{ }^{1} J_{\mathrm{FB}}=28.4 \mathrm{~Hz}, 2 \mathrm{~F}\right)$.

$\underline{\text { HRMS }}\left([\mathrm{M}-\mathrm{H}]^{+}\right.$) calculated for $\mathrm{M}=\mathrm{C}_{107} \mathrm{H}_{101} \mathrm{~N}_{10} \mathrm{O}_{8} \mathrm{BF}_{2}: 1701.7786$; detected $[\mathrm{M}-\mathrm{H}]^{+}:$1701.7720.

CHN theoretical (\%) C: 75.43, H: 5.98, N: 8.22; found (\%) C: 74.74; H: 6.02; N: 7.94. 


\section{NMR Spectra}

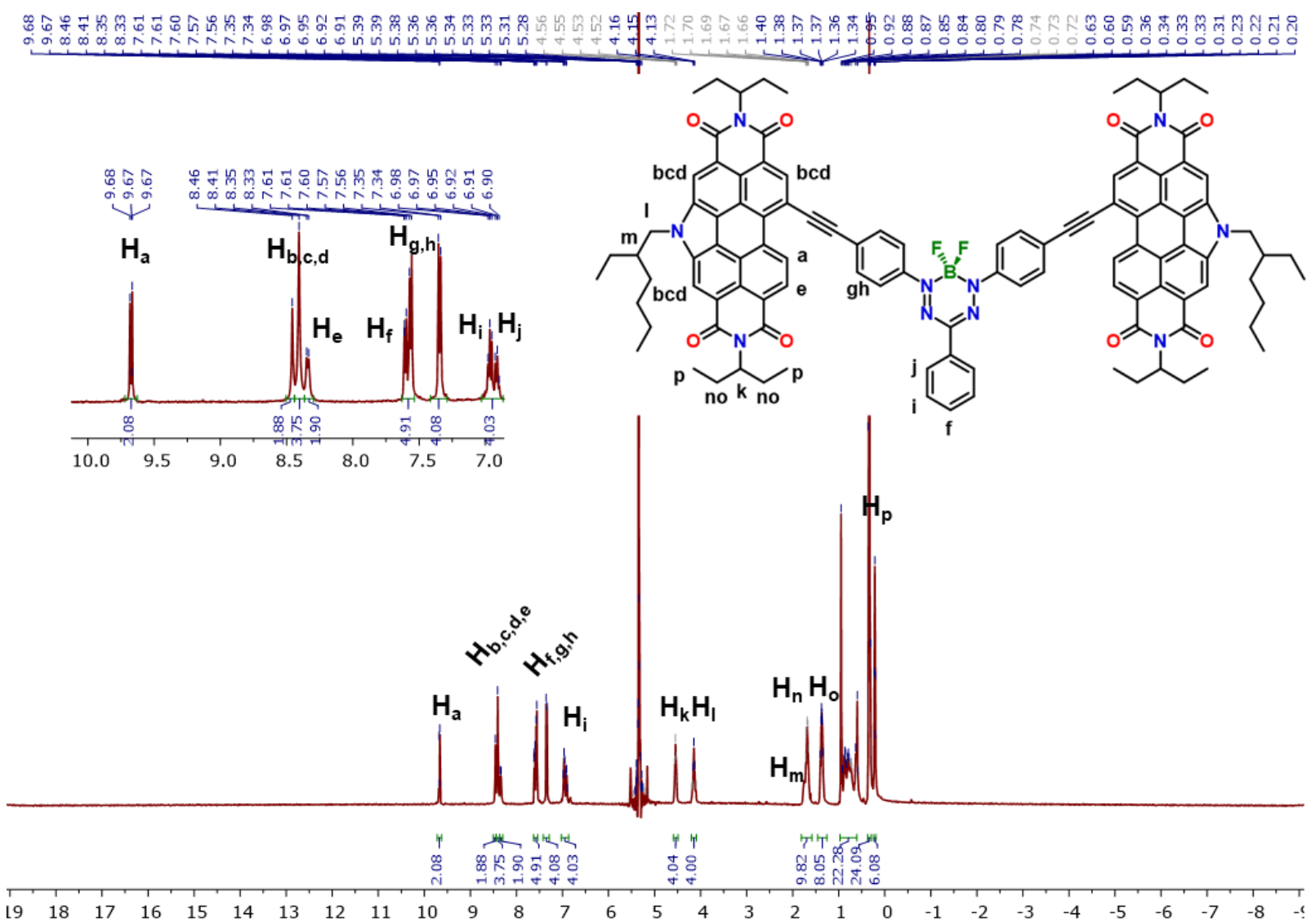

Fig. S1 ${ }^{1} \mathrm{H}$ NMR spectrum of $\mathrm{BF}_{2} \mathrm{PDI}_{2}\left(500 \mathrm{MHz}\right.$, Tetrachloroethane-d $\mathrm{d}_{2}$ ).
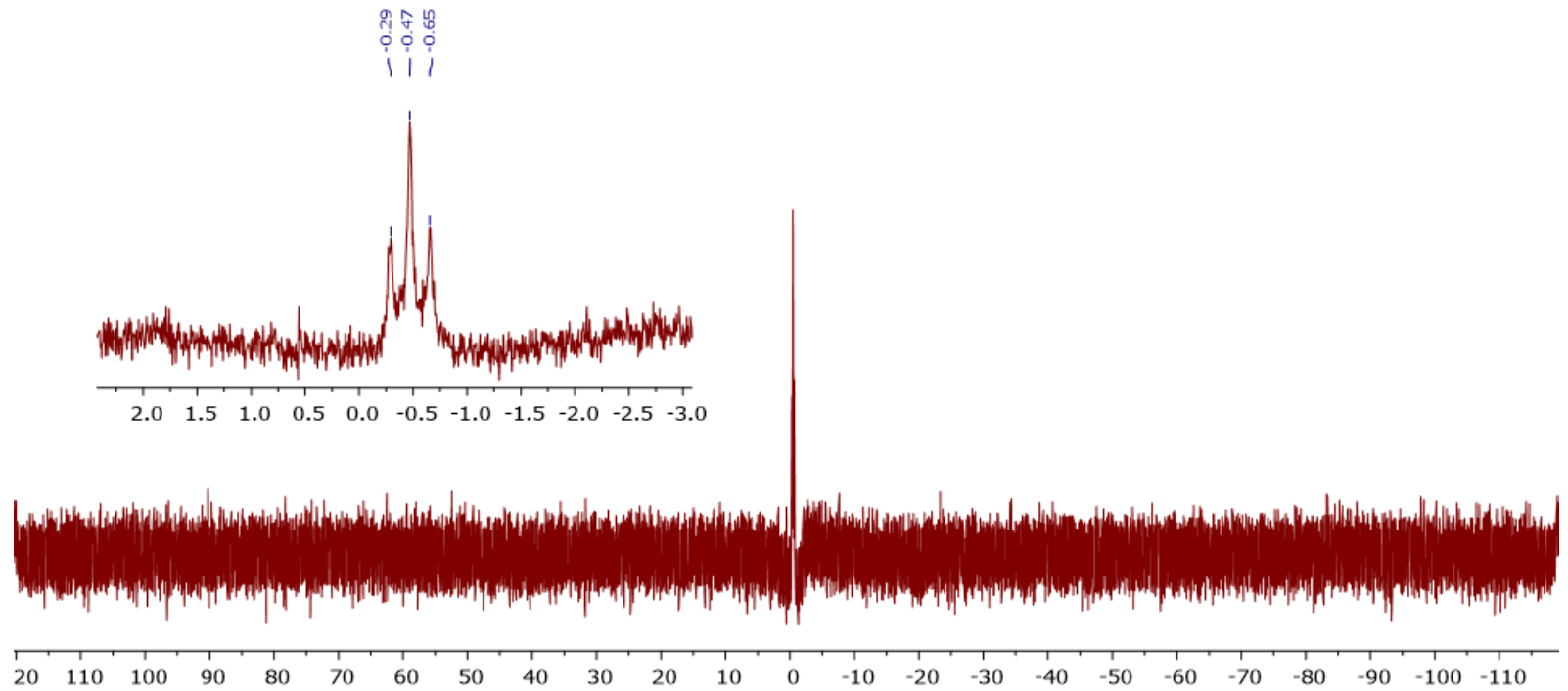

Fig. S2 ${ }^{11} \mathrm{~B}$ NMR spectrum of $\mathrm{BF}_{2} \mathrm{PDI}_{2}\left(161 \mathrm{MHz}\right.$, Tetrachloroethane- $\left.\mathrm{d}_{2}\right)$. 


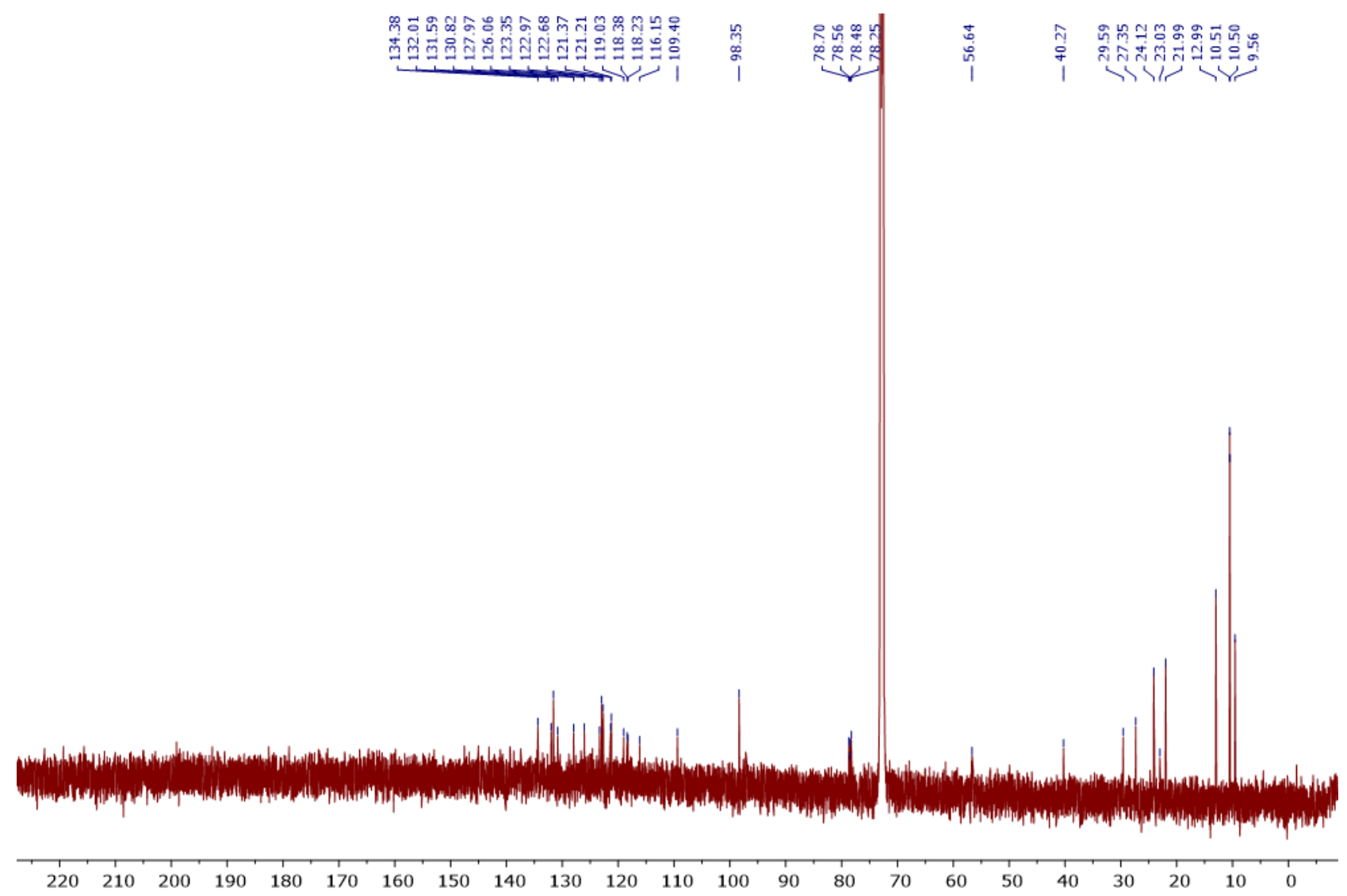

Fig. S3 ${ }^{13} \mathrm{C}\left\{{ }^{1} \mathrm{H}\right\}$ NMR spectrum of $\mathrm{BF}_{2} \mathrm{PDI}_{2}\left(126 \mathrm{MHz}\right.$, Tetrachloroethane- $\left.\mathrm{d}_{2}\right)$.

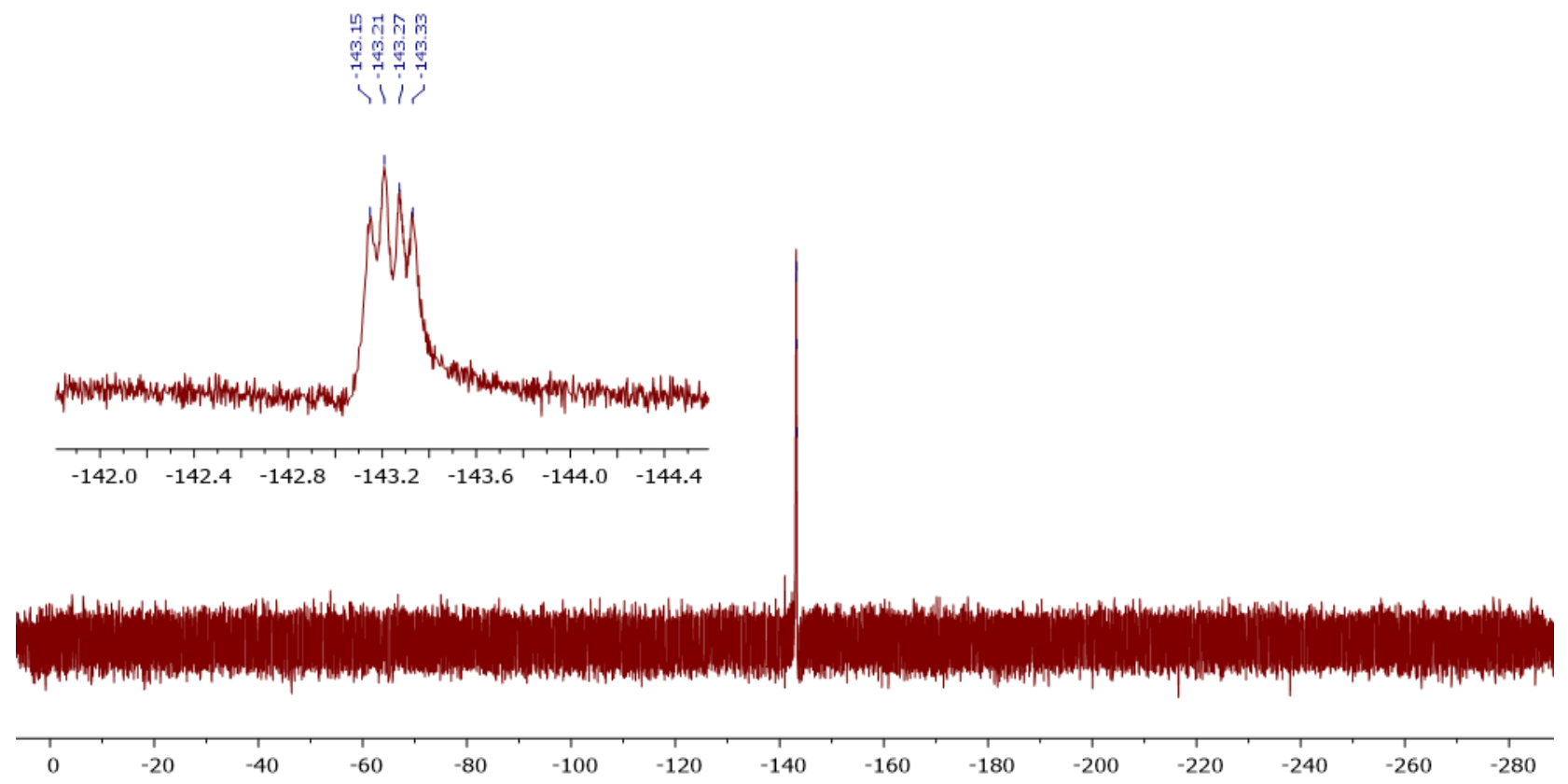

Fig. S4 ${ }^{19} \mathrm{~F}$ NMR spectrum of $\mathrm{BF}_{2} \mathrm{PDI}_{2}(471 \mathrm{MHz}$, Tetrachloroethane-d 2 ). 

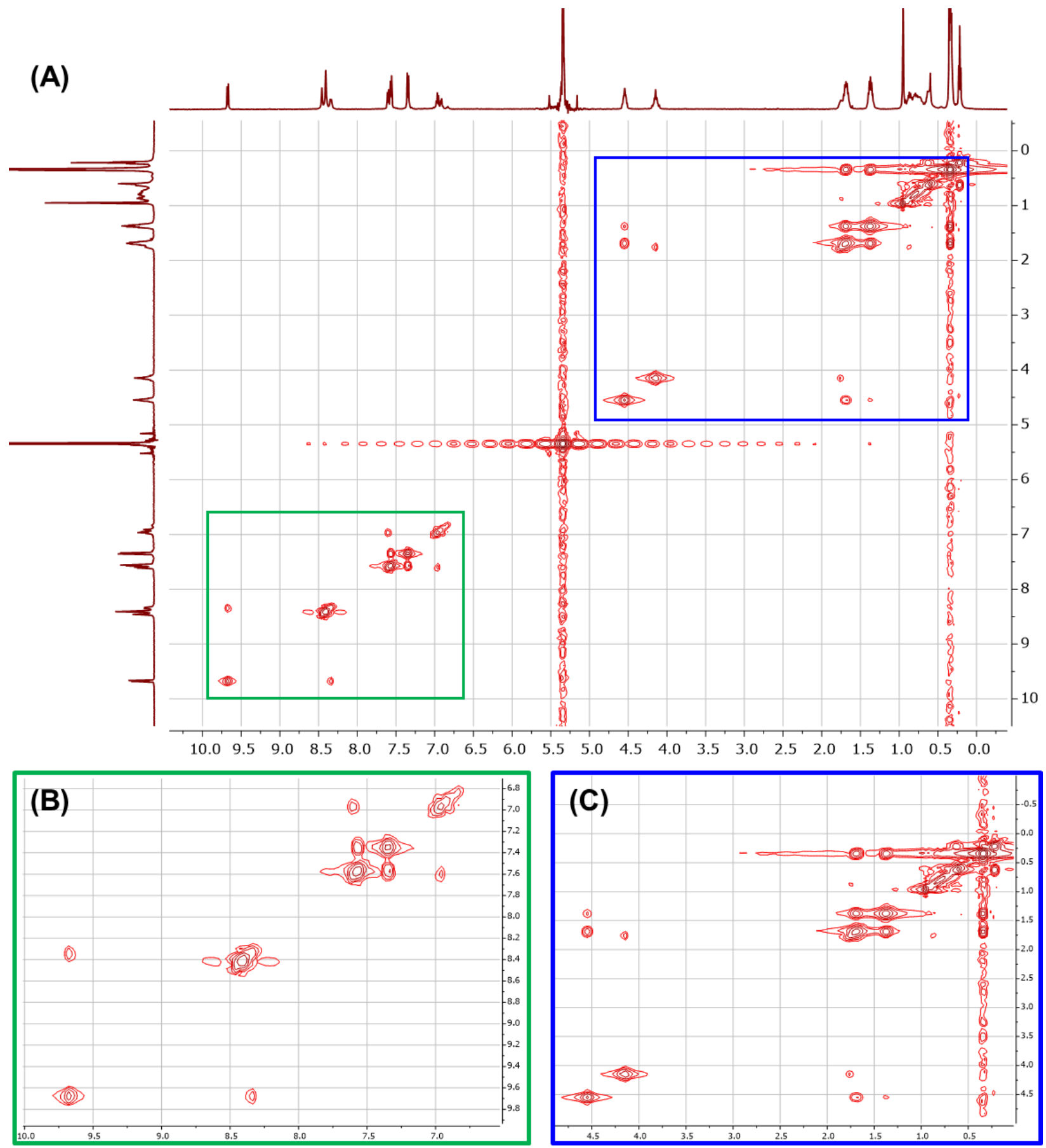

Fig. S5 ${ }^{1} \mathrm{H}-{ }^{1} \mathrm{H}$ COSY spectrum (A) of $\mathrm{BF}_{2} \mathrm{PDI}_{2}\left(500 \mathrm{MHz}\right.$, Tetrachloroethane- $\left.\mathrm{d}_{2}\right)$ with enhanced views of the aromatic (B) and aliphatic (C) regions. 


\section{MS, CHN EA, \& Thermal Properties}

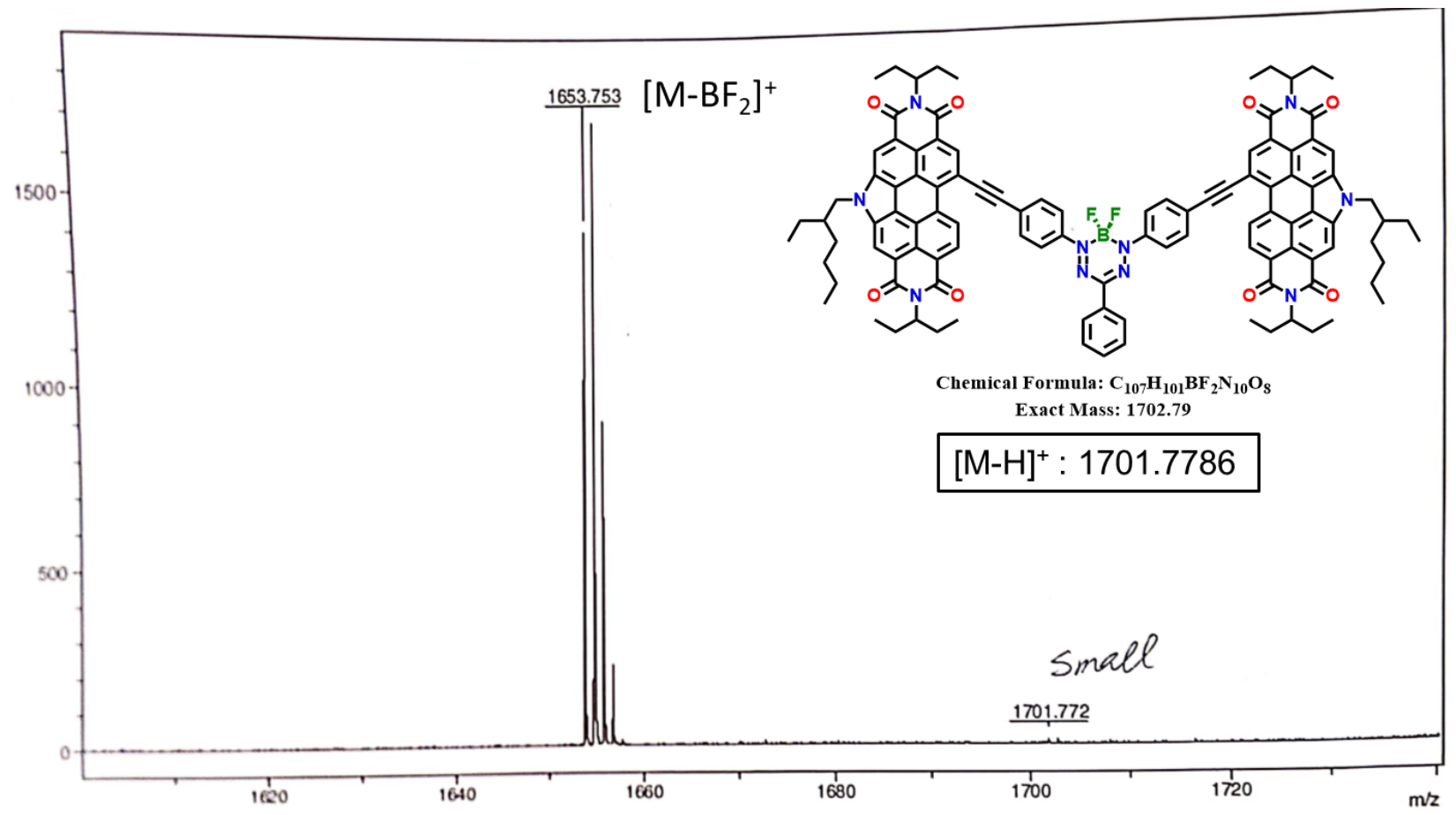

Fig. S6 HR MADLI TOF mass spectrum of $\mathrm{BF}_{2} \mathrm{PDI}_{2}$.

University of Calgary
Department of Chemistry EA Date: $2 / 5 / 2020$

\begin{tabular}{|c|c|c|c|}
\hline Name: & JOSH & Group: & \\
\hline Sample: & $\mathrm{BF}_{2} \mathrm{PDI}_{2}$ & Weight (mg): & 1.59 \\
\hline \%C (Actual): & 74.74 & \%C (Theorectical): & 75.43 \\
\hline \%H (Actual): & 6.02 & \%H (Theoretical): & 5.98 \\
\hline$\% N$ (Actual): & 7.94 & $\% \mathrm{~N}$ (Theoretical): & 8.22 \\
\hline
\end{tabular}

Fig. S7 CHN elemental analysis of $\mathrm{BF}_{2} \mathrm{PDI}_{2}$. 


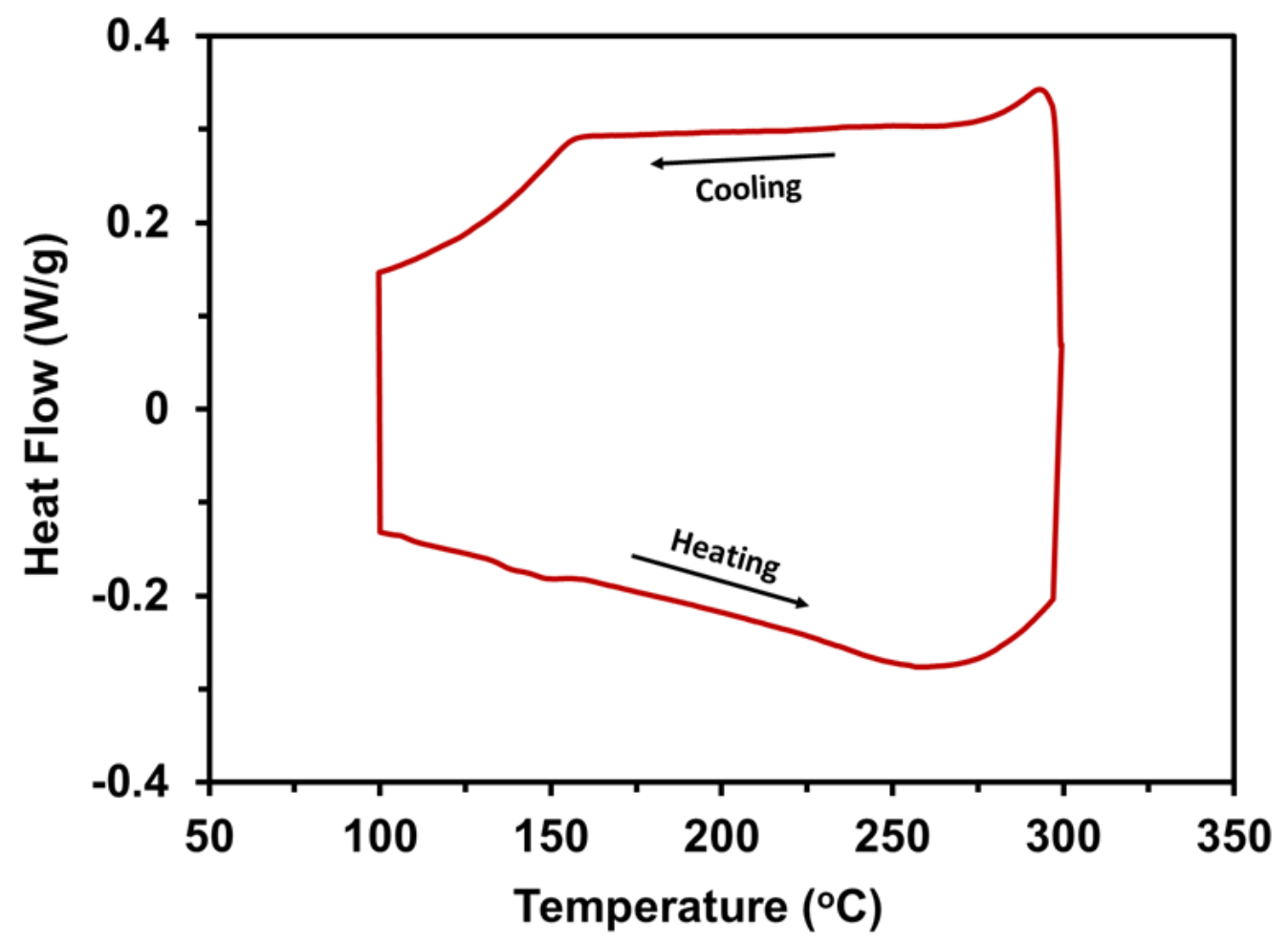

Fig. S8 Differential scanning calorimetry profile of $\mathrm{BF}_{2} \mathrm{PDI}_{2}$.

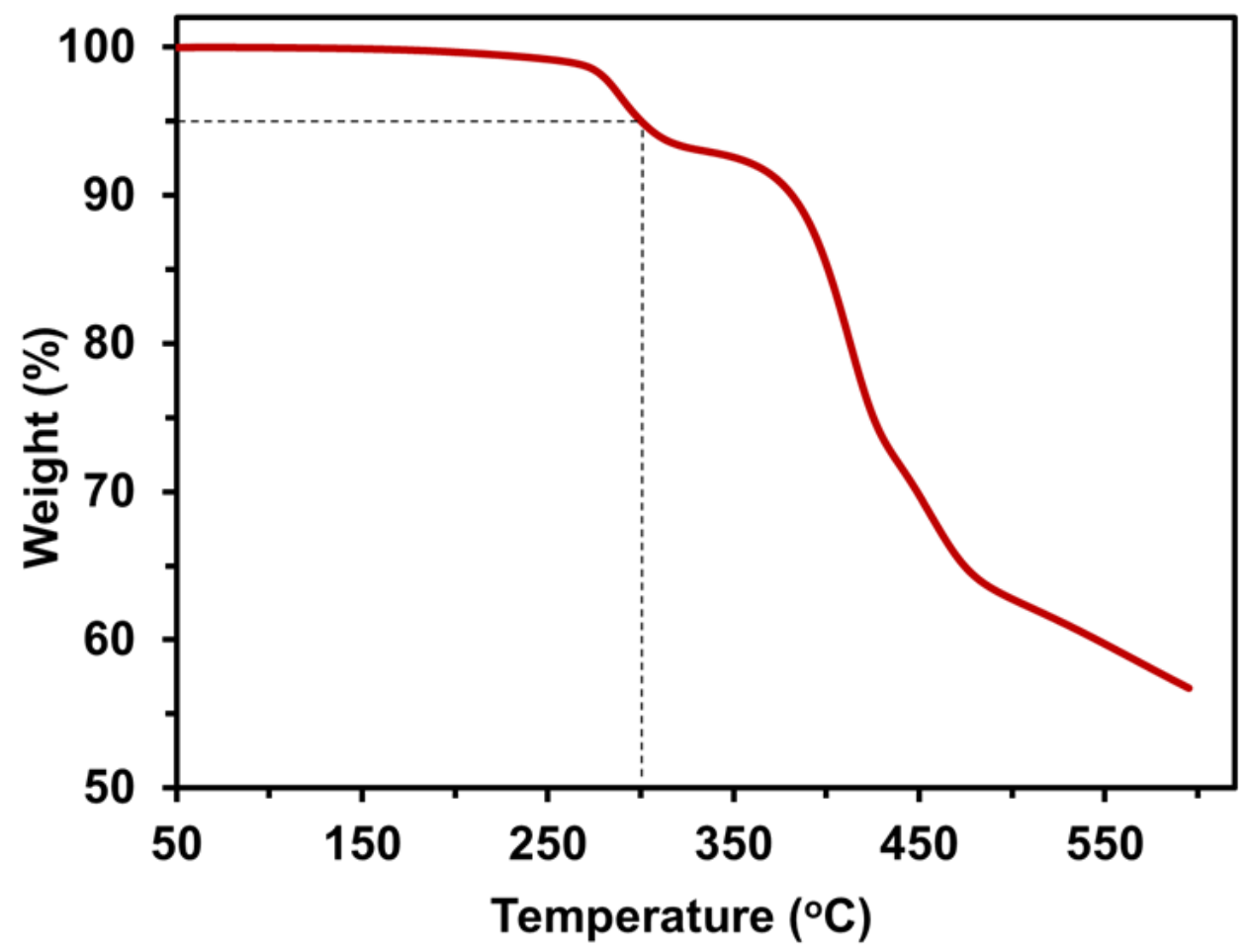

Fig. S9 Thermal gravimetric analysis profile of $\mathrm{BF}_{2} \mathrm{PDI}_{2}$. 


\section{UV-Visible Spectroscopy}

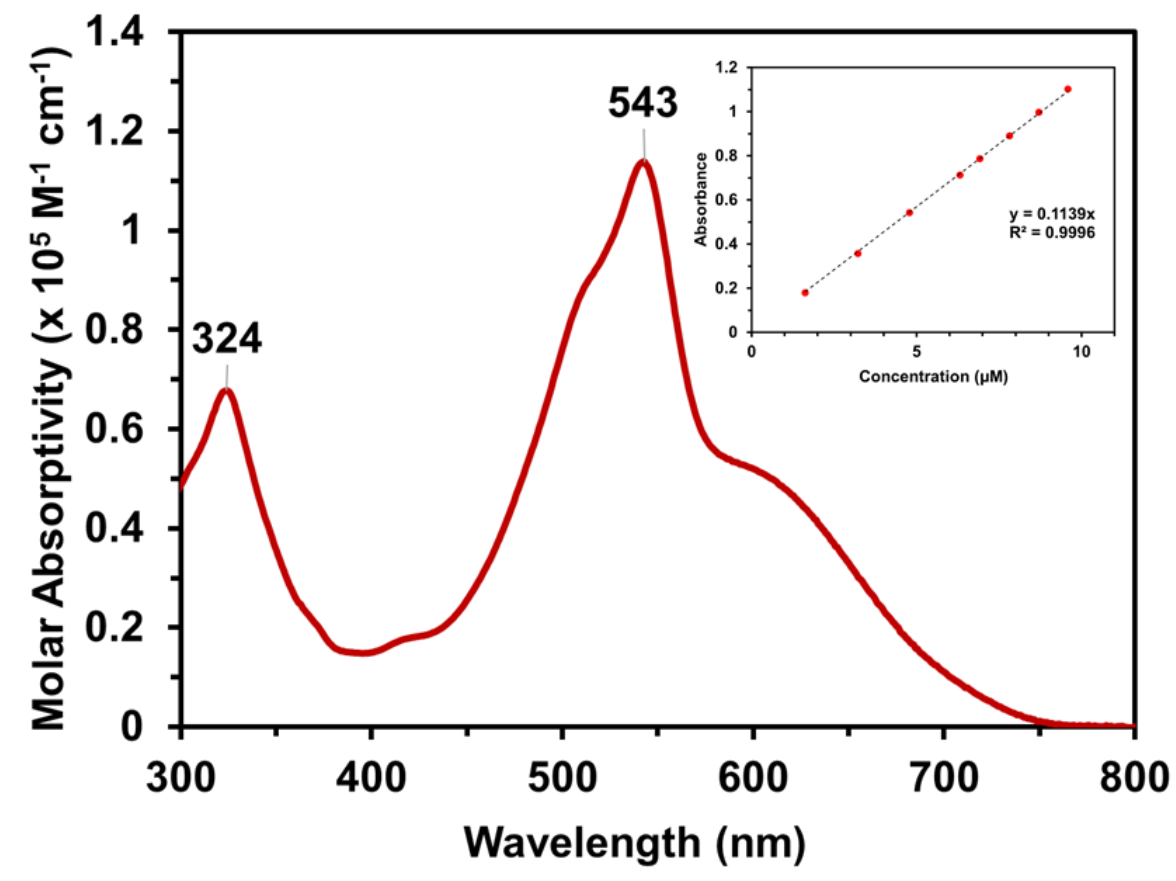

Fig. S10 UV-visible absorption spectrum of $\mathrm{BF}_{2} \mathrm{PDI}_{2}$ in $\mathrm{CHCl}_{3}$, with calibration curve inset.

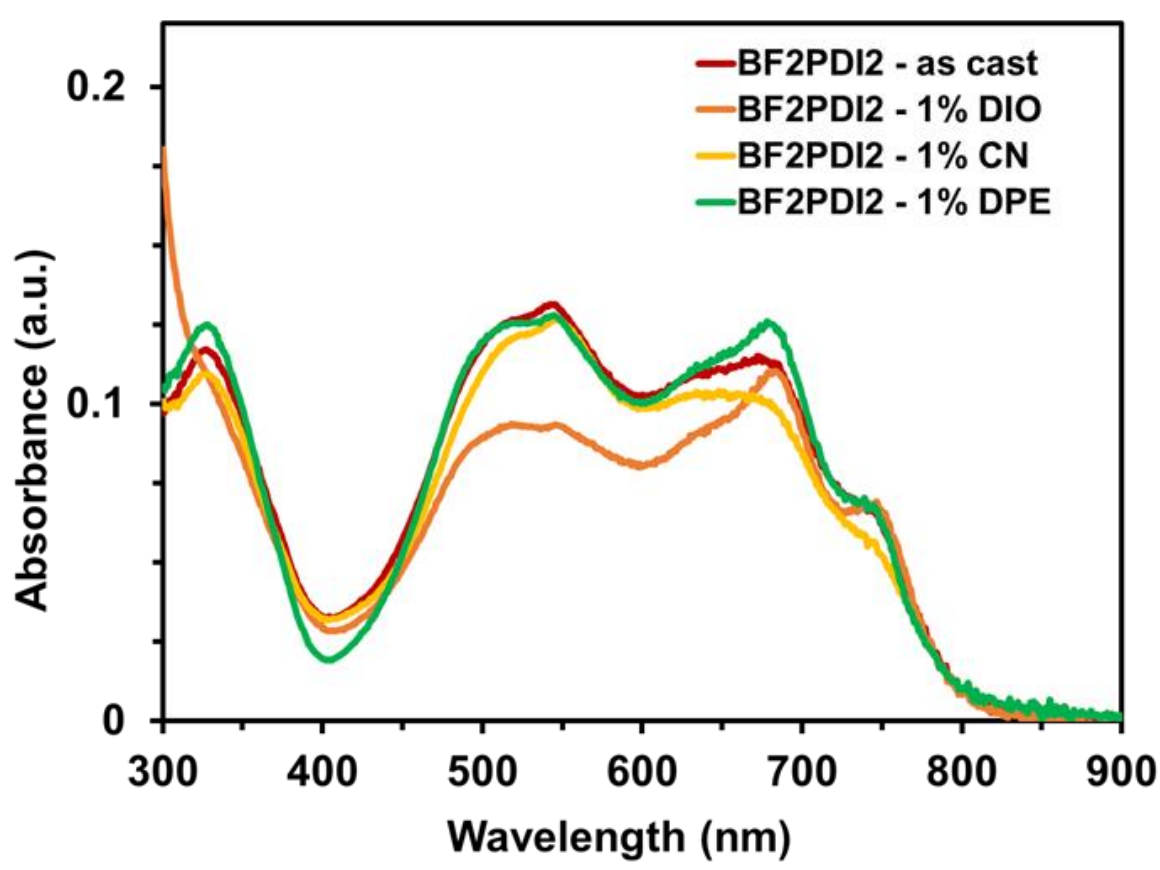

Fig. S11 Comparing the influence of solvent additives 1,8-diiodooctane (DIO), 1chloronaphthalene $(\mathrm{CN})$, and diphenyl ether (DPE) on the thin film UV-vis absorption spectra of $\mathrm{BF}_{2} \mathrm{PDI}_{2}$ (spin-coated from $10 \mathrm{mg} / \mathrm{mL} o$-DCB solutions). 


\section{Electrochemistry}

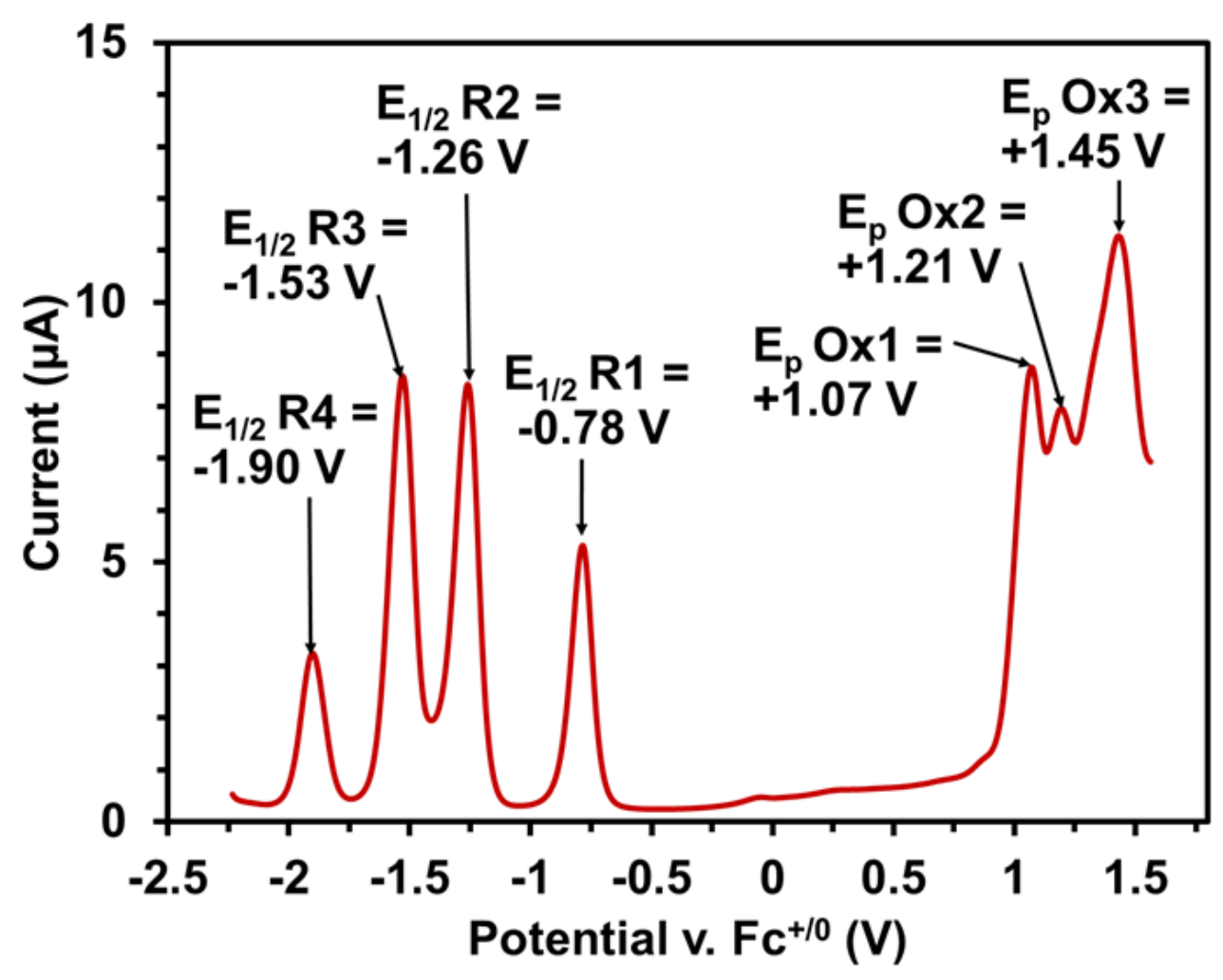

Fig. S12 Differential pulse voltammogram of $\mathrm{BF}_{2} \mathrm{PDI}_{2}$, measured in $\mathrm{CH}_{2} \mathrm{Cl}_{2}$ under argon with 0.1 $\mathrm{M} \mathrm{TBAPF}_{6}$ supporting electrolyte $(\mathrm{WE}=$ glassy carbon, $\mathrm{CE}=\mathrm{Pt}$-wire, sseudo- $\mathrm{RE}=\mathrm{Ag} / \mathrm{AgCl})$. 


\section{Density Functional Theory}

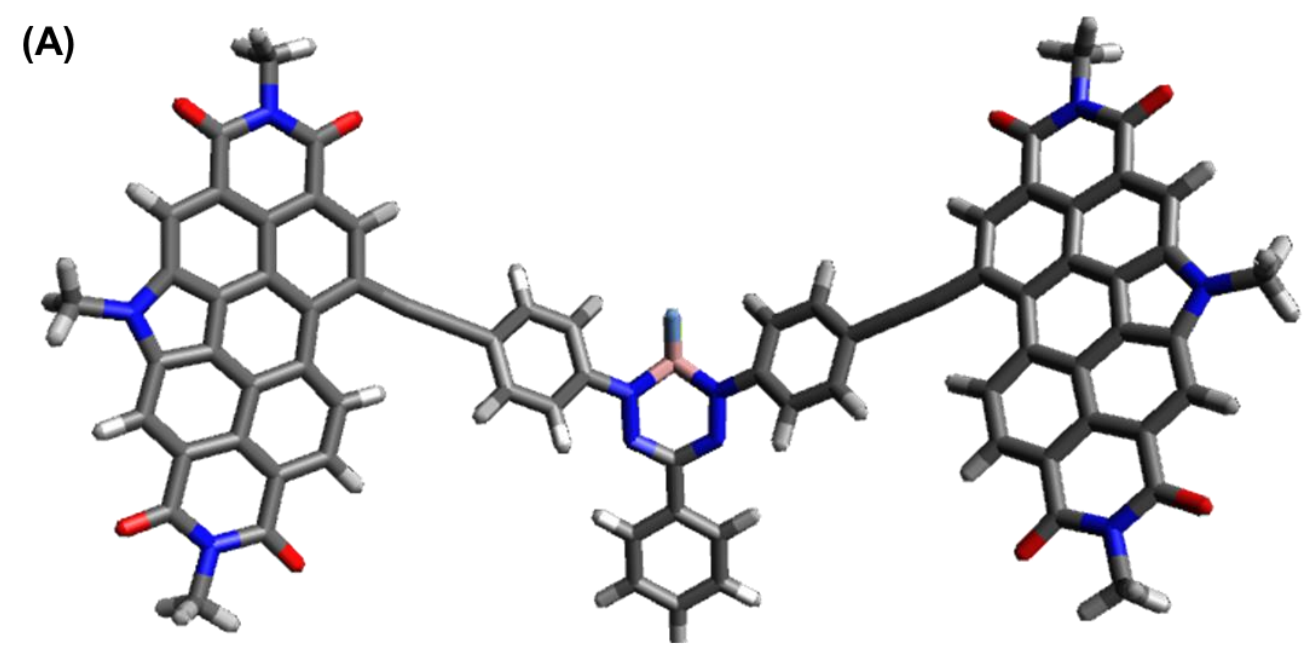

(B)

(C)
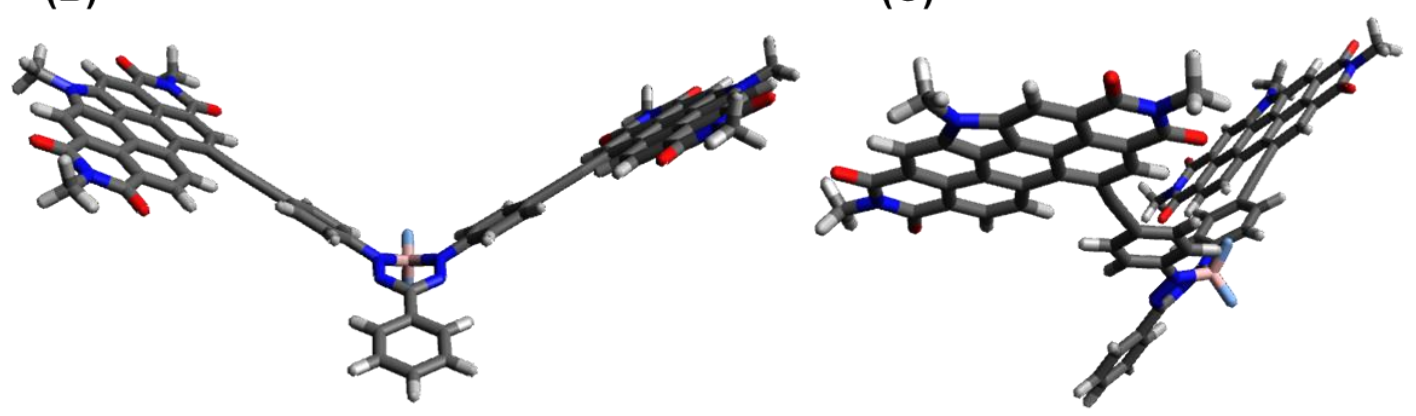

Fig. S13 Optimized geometry for $\mathrm{BF}_{2} \mathrm{PDI}_{2}$ at $\mathrm{B} 3 \mathrm{LYP} / 6-31 \mathrm{G}(\mathrm{d}, \mathrm{p})$ ground-state.
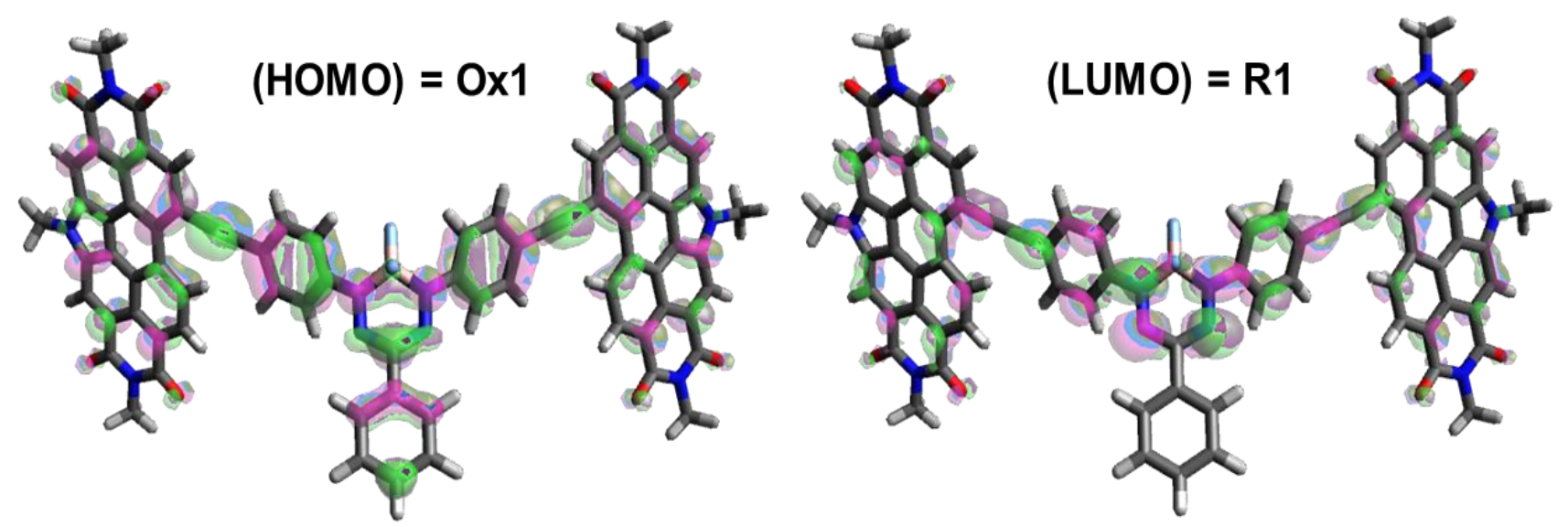

Fig. S14 Highest occupied molecular orbital (HOMO) and the lowest unoccupied molecular orbital (LUMO) for $\mathrm{BF}_{2} \mathrm{PDI}_{2}$ at $\mathrm{B} 3 \mathrm{LYP} / 6-31 \mathrm{G}(\mathrm{d}, \mathrm{p})$ ground-state. 


\section{OPV Device Data}

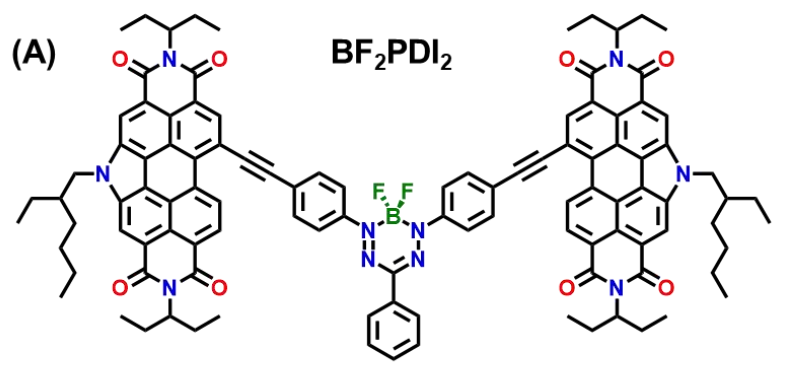

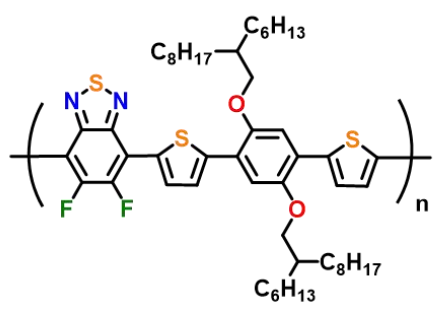

PPDT2FBT

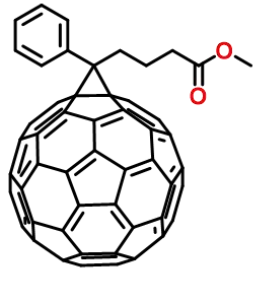

$\mathrm{PC}_{61} \mathrm{BM}$

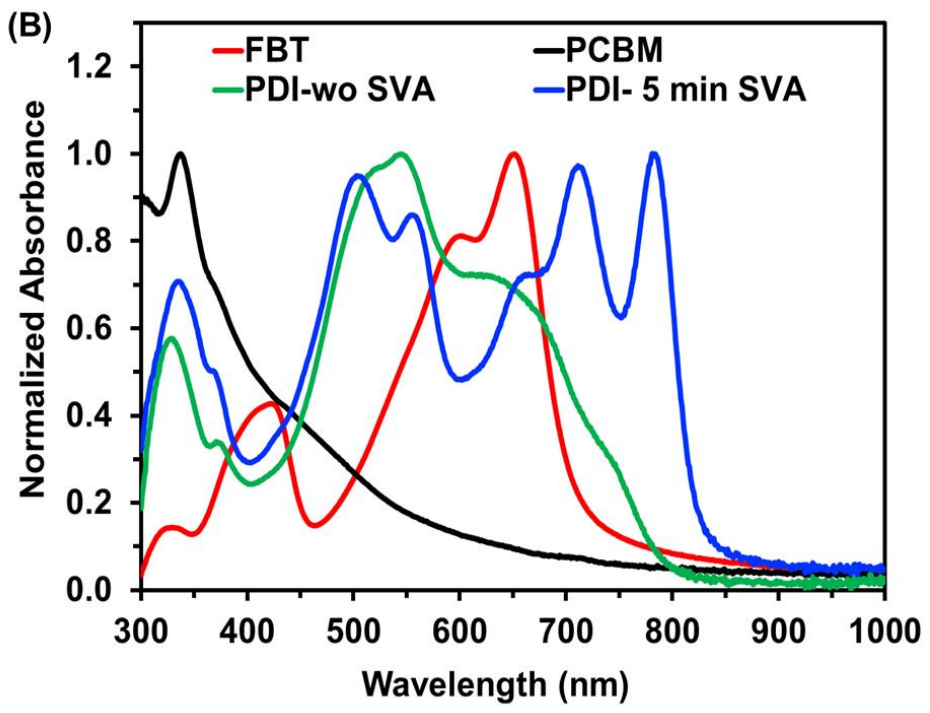

Fig. S15 Chemical structures (A) and film optical absorption profiles (B) of all components used in the OPV ternary blend active layer. $\mathrm{PDI}=\mathrm{BF}_{2} \mathrm{PDI}_{2}, \mathrm{PCBM}=\mathrm{PC}_{61} \mathrm{BM}, \mathrm{FBT}=\mathrm{PPDT} 2 \mathrm{FBT}$ in the plot. SVA = solvent vapour annealing for 5 min using $\mathrm{CHCl}_{3}$.

Table S1 Photovoltaic parameters of the devices based on ternary blend (PPDT2FBT: $\mathrm{BF}_{2} \mathrm{PDI}_{2}$ : $\left.\mathrm{PC}_{61} \mathrm{BM}\right)$. Metrics corresponding to the devices with the average PCE are in parenthesis.

\begin{tabular}{|c|c|c|c|c|}
\hline PPDT2FBT: $\mathrm{BF}_{2} \mathrm{PDI}_{2}: \mathrm{PC}_{61} \mathrm{BM}$ & $V_{o c}(V)$ & $\mathrm{J}_{s c}\left(\mathrm{~mA} / \mathrm{cm}^{2}\right)$ & $F F \%$ & РCE\% \\
\hline As-cast $(1: 1: 0.5,10 \mathrm{mg} / \mathrm{mL})$ & $0.69(0.69)$ & $1.10(1.02)$ & $41.3(40.1)$ & $0.31(0.28)$ \\
\hline $5 \mathrm{~min} \operatorname{SVA}(1: 1: 0.5,10 \mathrm{mg} / \mathrm{mL})$ & $0.64(0.65)$ & $1.95(1.84)$ & $48.6(47.8)$ & $0.61(0.57)$ \\
\hline
\end{tabular}



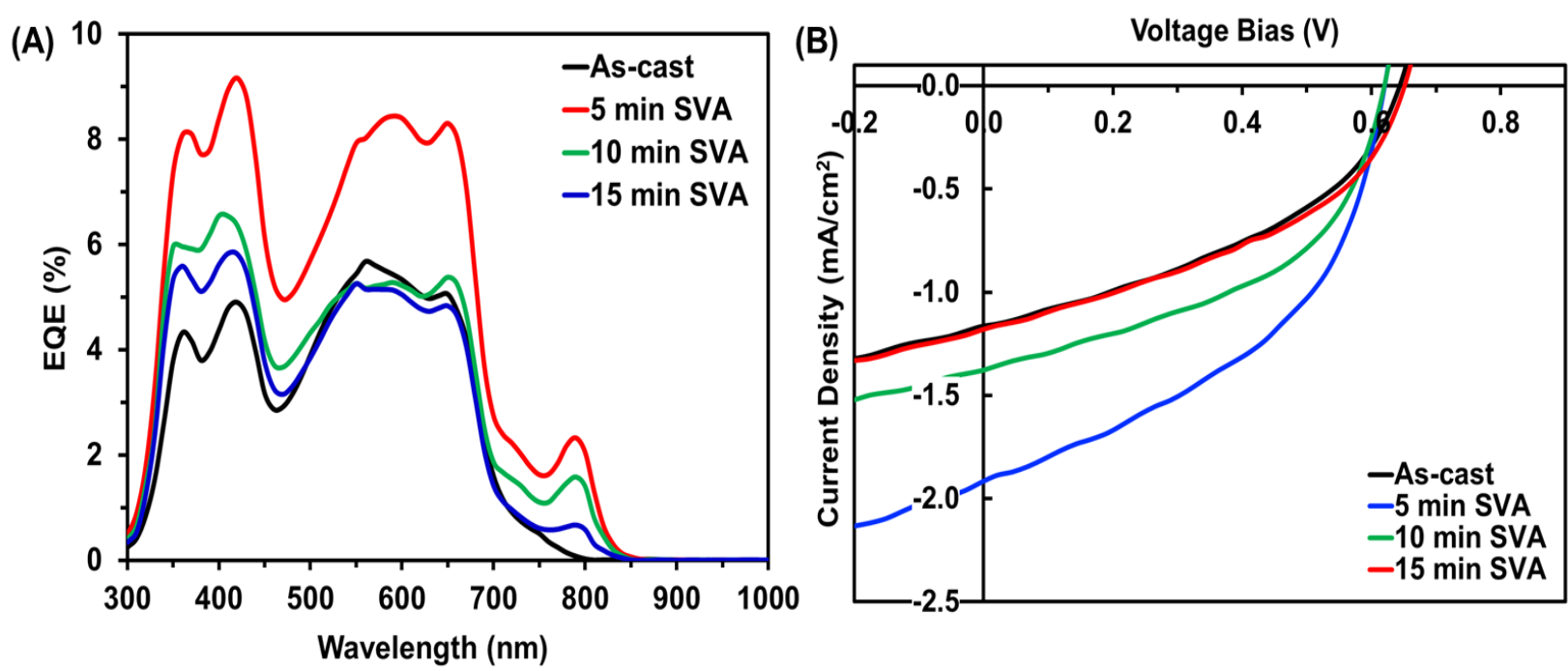

Fig. S16 External quantum efficiency plots (A) and J-V curves (B) comparing the effects of solvent vapor annealing duration on ternary blend OPV devices with PPDT2FBT: $\mathrm{BF}_{2} \mathrm{PDI}_{2}$ : $\mathrm{PC}_{61} \mathrm{BM}_{4}$ $(1: 1: 0.5)$ active layer at $10 \mathrm{mg} / \mathrm{mL}$ total concentration.

Table S2 Photovoltaic parameters of the devices based on ternary blend (PPDT2FBT: $\mathrm{BF}_{2} \mathrm{PDI}_{2}$ : $\left.\mathrm{PC}_{61} \mathrm{BM}\right)$, comparing the effects of SVA treatment duration.

\begin{tabular}{|c|c|c|c|c|}
\hline PPDT2FBT: $\mathrm{BF}_{2} \mathrm{PDI}_{2}: \mathrm{PC}_{61} \mathrm{BM}$ & $V_{o c}(V)$ & $\begin{array}{c}\mathbf{J}_{s c} \\
\left(\boldsymbol{m A / c m ^ { 2 }}\right)\end{array}$ & $F F(\%)$ & $P C E(\%)$ \\
\hline As-cast $(1: 1: 0.5,10 \mathrm{mg} / \mathrm{mL})$ & 0.64 & 1.17 & 41 & 0.31 \\
\hline $5 \mathrm{~min}$ SVA $(1: 1: 0.5,10 \mathrm{mg} / \mathrm{mL})$ & 0.62 & 1.91 & 45 & 0.53 \\
\hline $10 \mathrm{~min} \operatorname{SVA}(1: 1: 0.5,10 \mathrm{mg} / \mathrm{mL})$ & 0.62 & 1.37 & 47 & 0.41 \\
\hline $15 \min \operatorname{SVA}(1: 1: 0.5,10 \mathrm{mg} / \mathrm{mL})$ & 0.65 & 1.18 & 41 & 0.32 \\
\hline
\end{tabular}



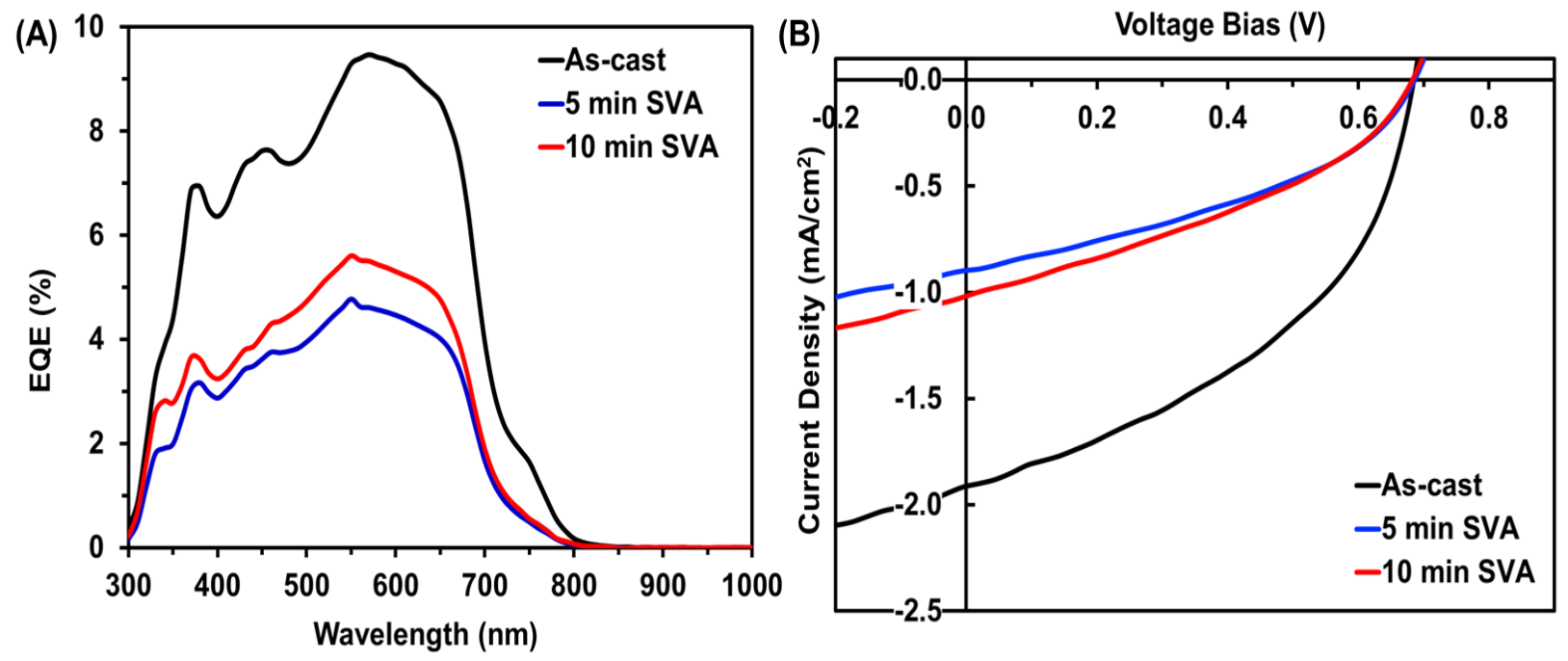

Fig. S17 External quantum efficiency plots (A) and J-V curves (B) comparing the effects of solvent vapor annealing duration on ternary blend OPV devices with PPDT2FBT: $\mathrm{BF}_{2} \mathrm{PDI}_{2}$ : $\mathrm{PC}_{61} \mathrm{BM}$ (1:0.75:0.75) active layer at $20 \mathrm{mg} / \mathrm{mL}$ total concentration.

Table S3 Photovoltaic parameters of the devices based on ternary blend (PPDT2FBT: $\mathrm{BF}_{2} \mathrm{PDI}_{2}$ : $\left.\mathrm{PC}_{61} \mathrm{BM}\right)$, comparing the effects of solvent vapor annealing on an altered the ternary blend.

\begin{tabular}{ccccc}
$\boldsymbol{P P D T} 2 \boldsymbol{F B T}: \boldsymbol{B F}_{2} \boldsymbol{P D I}_{2}: \boldsymbol{P C}_{\boldsymbol{6}} \boldsymbol{B M}$ & $\boldsymbol{V}_{\boldsymbol{o c}}(\boldsymbol{V})$ & $\mathbf{J}_{\boldsymbol{s c}}\left(\boldsymbol{m A} / \mathbf{c m}^{2}\right)$ & $\boldsymbol{F F}(\%)$ & $\boldsymbol{P C E}(\%)$ \\
\hline As-cast (1:0.75:0.75, 20 mg/mL) & 0.68 & 1.91 & 44 & 0.58 \\
5 min SVA (1:0.75:0.75, 20 mg/mL) & 0.68 & 0.90 & 39 & 0.24 \\
10 min SVA (1:0.75:0.75, $20 \mathrm{mg} / \mathrm{mL})$ & 0.68 & 1.01 & 36 & 0.25
\end{tabular}




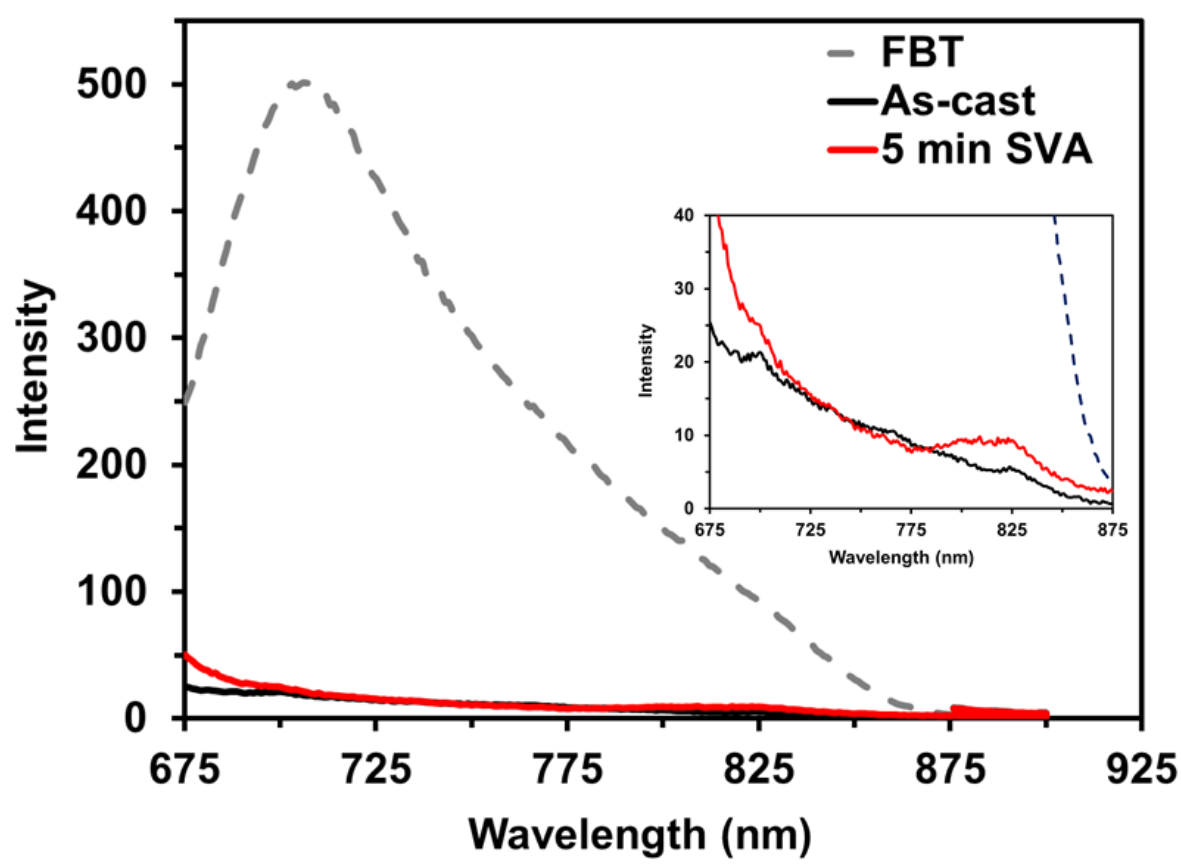

Fig. S18 Photoluminescence spectra of OPV devices with PPDT2FBT: $\mathrm{BF}_{2} \mathrm{PDI}_{2}: \mathrm{PC}_{61} \mathrm{BM}$ (1:1:0.5) active layer at $10 \mathrm{mg} / \mathrm{mL}$ total concentration, before (black) and after (red) solvent vapor annealing from $\mathrm{CHCl}_{3}$. The excitation wavelength was $651 \mathrm{~nm}$.

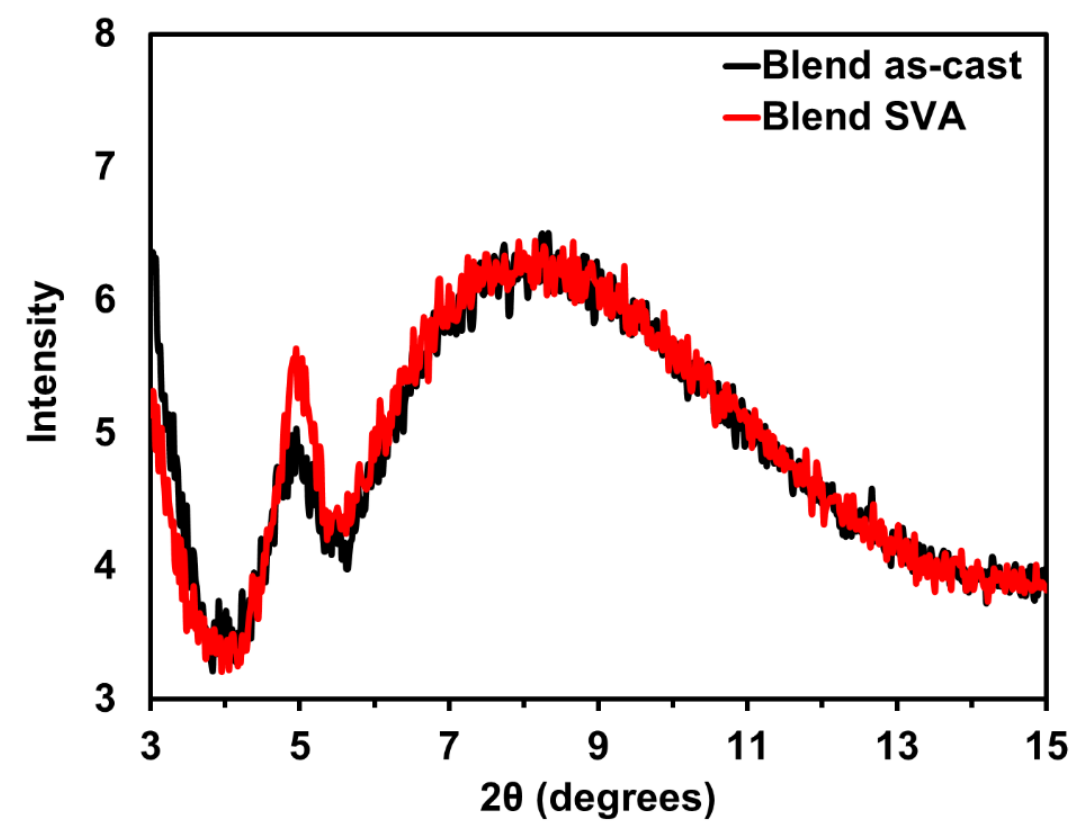

Fig. S19 X-ray diffraction spectra of spin-cast PPDT2FBT: $\mathrm{BF}_{2} \mathrm{PDI}_{2}: \mathrm{PC}_{61} \mathrm{BM}$ (1:1:0.5), before (black) and after (red) solvent vapor annealing from $\mathrm{CHCl}_{3}$. 


\section{References}

1 J. Pommerehne, H. Vestweber, W. Guss, R. F. Mahrt, H. Bässler, M. Porsch and J. Daub, Adv. Mater., 1995, 7, 551-554.

2 Y. Sun, J. H. Seo, C. J. Takacs, J. Seifter and A. J. Heeger, Adv. Mater., 2011, 23, 1679-1683.

3 Frisch, M. J.; Trucks, G. W.; Schlegel, H. B.; Scuseria, G. E.; Robb, M. A.; Cheeseman, J. R.; Scalmani, G.; Barone, V.; Petersson, G. A.; Nakatsuji, H.; Li, X.; Caricato, M.; Marenich, A. V.; Bloino, J.; Janesko, B. G.; Gomperts, R.; Mennucci, B.; Hratchian, H. P.; Ortiz, J. V.; Izmaylov, A. F.; Sonnenberg, J. L.; Williams-Young, D.; Ding, F.; Lipparini, F.; Egidi, F.; Goings, J.; Peng, B.; Petrone, A.; Henderson, T.; Ranasinghe, D.; Zakrzewski, V. G.; Gao, J.; Rega, N.; Zheng, G.; Liang, W.; Hada, M.; Ehara, M.; Toyota, K.; Fukuda, R.; Hasegawa, J.; Ishida, M.; Nakajima, T.; Honda, Y.; Kitao, O.; Nakai, H.; Vreven, T.; Throssell, K.; Montgomery, J. A., Jr.; Peralta, J. E.; Ogliaro, F.; Bearpark, M. J.; Heyd, J. J.; Brothers, E. N.; Kudin, K. N.; Staroverov, V. N.; Keith, T. A.; Kobayashi, R.; Normand, J.; Raghavachari, K.; Rendell, A. P.; Burant, J. C.; Iyengar, S. S.; Tomasi, J.; Cossi, M.; Millam, J. M.; Klene, M.; Adamo, C.; Cammi, R.; Ochterski, J. W.; Martin, R. L.; Morokuma, K.; Farkas, O.; Foresman, J. B.; Fox, D. J Gaussian 09 Revis. E01 Gaussian Inc Wallingford CT.

4 S. M. Barbon and J. B. Gilroy, Polym. Chem., 2016, 7, 3589-3598.

5 A. D. Hendsbee, J.-P. Sun, W. K. Law, H. Yan, I. G. Hill, D. M. Spasyuk and G. C. Welch, Chem. Mater., 2016, 28, 7098-7109. 